\title{
Deep Eutectic Solvents: The Organic Reaction Medium of the Century
}

\author{
Diego A. Alonso, ${ }^{*[a]}$ Alejandro Baeza, ${ }^{*[a]}$ Rafael Chinchilla, ${ }^{*[a]}$ Gabriela Guillena, ${ }^{*[a]}$ Isidro M. Pastor, ${ }^{*[a]}$ \\ and Diego J. Ramón*[a] \\ Dedication ((optional))
}

\begin{abstract}
This microreview summarizes the use of deep eutectic solvents (DES) and related melts in Organic Synthesis. This type of solvents combine the great advantages of other proposed environmentally benign alternative solvents, such as low toxicity, high availability, low inflammability, high recyclability, low volatility and low price, avoiding many disadvantages of these neoteric media. The fact that many of the components of the mixture come directly from Nature assures their biodegradability and renewability. The classification and distribution of the reactions in different sections along this microreview, as well as the emphasis paid to their scope, easily allows a general reader to understand the actual state of art, and the great opportunities opened, not only for academic proposes but also for industry.
\end{abstract}

\section{Introduction}

On 8 September 2000, following a three day Millennium Summit of World leaders at the headquarters of the United Nations, the General Assembly adopted the Millennium Declaration. The outcome of the resolution was passed by the General Assembly on 14 December 2000 to guide its implementation. The Millennium Declaration has eight chapters and key objectives, and the $4^{\text {th }}$ objective is entitled "Protecting our common environment". [1] Five years later, the United Nations General Assembly identified principles and treaties on sustainable development, including economic, and social development, as well as environmental protection. These principles are the crystallization of social worries which re-started in the middle of the seventies, with the petrol crisis. In time, Western society was made conscious of the limited fuel and raw material resources, as well as the noxious balance in the equilibrium of our environmental surroundings. Since then, chemists have proposed and developed methods, and technologies to provide an answer to these social demands.

In 2005, it was reported that solvents constituted $80-90 \%$ of non-aqueous mass of materials used to make an active pharmaceutical ingredient (API). ${ }^{[2]}$ In fact, solvents are ubiquitous in Chemistry and are used in large amount for a variety of products, including paints, coatings, adhesives, as raw material for product synthesis, as reaction media, and for equipment cleaning. So, making the correct choice is the main variable which

[a] D. A, Alonso, A. Baeza, R. Chinchilla, G. Guillena, I. M. Pastor, D. J. Ramón

Instituto de Síntesis Orgánica, and Dpto. de Química Orgánica Universidad de Alicante

Apdo. 99, E-03080-Alicante, Spain

E-mail: Diego.Alonso@ua.es, alex.baeza@ua.es, chinchilla@ua.es, gabriela.guillena@ua.es,ipastor@ua.es,djramon@ua.es http://personal.ua.es/en/djramon/ can change the sustainability of a process. ${ }^{[3]}$ In fact, some chemical industries have strict protocols in order to reach this goal. ${ }^{[4]}$

Diego A. Alonso studied chemistry at the University of Alicante receiving there his B.Sc. (1992) and Ph.D. (1997) degrees. After his postdoctorate period (1997-1999) with Prof. Pher G. Andersson at Uppsala University working on asymmetric catalysis, he returned to the University of Alicante as a senior scientist and Ramón y Cajal researcher (2001). In 2003 he became Associate Professor at the same university. In 2015 he has obtained the habilitation for

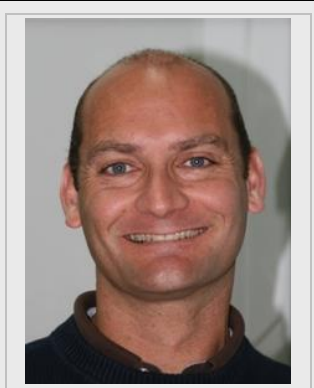
becoming full professor. Diego Alonso has been visiting scientist at Groningen University with Prof. Ben L. Feringa (2005) and at The Scripps Research Institute with Prof. Carlos F.Barbas, III (2007). His research interests are focused on organometallic catalysis, asymmetric organocatalysis, green chemistry, and material science.

Alejandro Baeza was born in Alicante (Spain) in 1979. After studying chemistry at the University of Alicante, he received the M.Sc. (2003) and Ph. D. degrees (2006) from the same university. In 2007 he joined Prof. Pfaltz group in Basel University as postdoctoral researcher where he spent 3 years. In 2010 he moved back to Alicante working as associate researcher until date. His main research interests are focused in the development of new methodologies, especially in asymmetric catalysis area.

Rafael Chinchilla was born in Alicante and studied chemistry at the University of Alicante from which he was graduated (1985) and doctorated (1990). After a postdoctoral stay at the University of Uppsala (1991-1992) with Prof. J.-E. Bäckvall, he moved back to the University of Alicante where he was appointed Associate Professor in 1997 and Full Professor in 2012. His research interests are mainly focused on enantioselective syntheses by using organocatalysis.
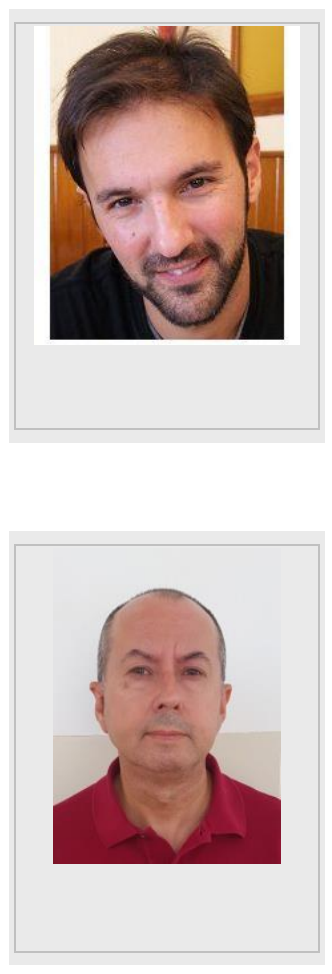
When common volatile organic compounds (VOC) used as solvents are regarded from an environmental point of view, they show many intrinsic drawbacks, such as accumulation in the atmosphere (low boiling points), flammability, high toxicity, and non-biodegradability.

Gabriela Guillena was born in Alicante (Spain) in 1970 and received her B.Sc. degree (1993) from the University of Alicante. After spending one year as postgraduate student in the group of Prof. D. Seebach (ETH, Zürich), she returned to the University of Alicante and received her M.Sc. (1995) and Ph.D. (2000) degrees. After two years as a postdoctoral fellow in the research group of Prof. G. van Koten (University of Utrecht, Netherlands), she returned to the University of Alicante where she became assistant professor (2003) and associate professor (2007). In 2015 she obtained the habilitation to become full professor. Her current research interest is focused on new organic methodologies and asymmetric organocatalysis.

Isidro M. Pastor conducted his chemistry studies at University of Alicante and received B.Sc. (1996) and M.Sc (1997) degrees. He obtained Ph.D. degree (2000, with Prof. M. Yus) by the same university. After two years as a postdoctoral fellow in the group of Prof. H. Adolfsson (Stockholm University, Sweden), he returned to the University of Alicante. He became associate professor at this university in 2010. His research interests are in the field of organometallic reagents, heterocyclic chemistry and catalysis.

Diego J. Ramón was born in Alicante (Spain) in 1965 and received his B.Sc. (1988), M.Sc. (1989), and Ph.D. (1993) degrees from the University of Alicante. After spending two years as a postdoctoral fellow at the ETHZentrum in Zürich, he returned to the University of Alicante and, after a short stay at Miguel Hernández University, became associate professor (2000) in the former university and was promoted to full professor in 2010 at the same university. He has been visiting professor at Debye Institute (University of Utrecht, Netherlands, 2001). In 1994, he was awarded the National Prize for Young Scientists of the Spanish Royal Society of Chemistry. His current research interest is focused on organometallic chemistry, asymmetric synthesis and environmentally benign processes.

However, when a systematic method for analyzing economic and environmental aspects of the raw materials, production, use, recycling, and final destruction of usual solvent is taken into account, the negative impact of them in the environment is even higher. ${ }^{[5]}$ In fact, "the best solvent is no solvent". ${ }^{[6,7]}$

Despite all these facts, a solvent is the common medium to carry out organic reactions due, among others, to the easy control of mass and heat transference, stabilization of transition states and fast modification of reactivity (rate, selectivity, etc.). To avoid the drawbacks of usual organic solvents, new media have been investigated, all of them having a certain number of advantages, as well as disadvantages.

Water can be considered the ideal solvent as it is very cheap, non-toxic, non-flammable, bio-renewable and safe for humans and environment. ${ }^{[8]}$ However, some limitations arise from the solubility of organic reagents and catalysts, the non-innocence of a solvent which could hydrolyze some organic functionalities, and the usual work-up of the reaction, that implies the final use of VOC solvents. Moreover, pure water is precious and when it is contaminated by chemicals, after being used as a solvent, purification is difficult and expensive.

Fluorinated solvents have been proposed as an alternative, since they are thermally and chemically stable, non-toxic and with very high gas solubility. ${ }^{[9]}$ However, their high price, together with their persistence in the atmosphere, does not make them very attractive.

Supercritical fluids, mainly $\mathrm{CO}_{2}{ }^{[10]}$ and water, ${ }^{[11]}$ could be another alternative, but the poor solubility of usual organic compounds in these systems, the high intrinsic reactivity of the solvent versus nucleophilic reagents, and the high cost of equipments for obtaining supercritical conditions, gave no options to these neoteric solvents to be considered as general.

Biomass-derived solvents, such as ethanol, limonene, ethyl lactate, ${ }^{[12]}$ glycerol, ${ }^{[13]}$ or 2-methyltetrahydrofuran,,${ }^{[14]}$ could be used as an excellent alternative to conventional organic solvents, since they are bio-renewable, safe and not very expensive. However, the possible modulation of their properties, or the complementary properties of each one, is not very high.

lonic liquids, generally composed by an organic cation, such as imidazolium or pyridinium core, and a weak nucleophilic and coordinating anion, have been denoted as the best alternative as they could have unusual solvent properties, poor coordinating activity, no actual pressure of vapor, non-flammability, stability at temperatures higher than $200{ }^{\circ} \mathrm{C}$, immiscibility with many organic solvents, possible fine tuning properties, and catalytic activity. ${ }^{[15]}$ Despite these virtues, the drawbacks are so important that they cannot be obviated. Thus, price, water stability, the need of using organic solvents at the end of the reaction, as well as the high toxicity and poor biodegradability ${ }^{[16]}$ are some of the most commented inconveniences. All these facts, together with their very low atom economy synthesis make their life cycle assessment very negative from an environmentally sustainable point of view.

As it was previously introduced, there is not an ideal alternative to the use of VOC's as solvents in organic synthesis. However, nowadays another reaction medium is recently evaluated: the use of eutectic mixtures as solvent to perform chemical transformations.

A eutectic mixture is the unique composition of two or more phase immiscible solid components which suffers a complete change of phase to liquid at a precise temperature (Figure 1). 


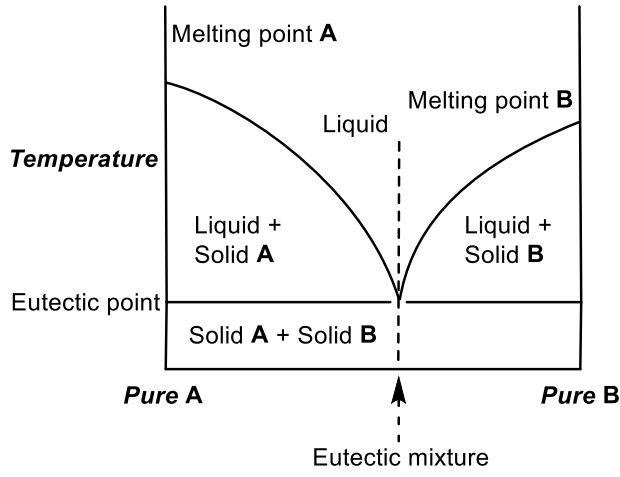

Figure 1. Phase diagram.
This point is called eutectic point and it is the minimum melting temperature in the whole set of compositions. This phenomenon occurs frequently when component atoms are small and can be placed in the interstitial spaces of the composite network formed by larger atoms, thus disrupting its crystalline pattern by diminishing the electrostatic forces and therefore triggering a decrease in the freezing point of the eutectic mixture.

Albeit eutectic mixtures have been known for decades, ${ }^{[17]}$ as well as their unusual reactivity near the eutectic point, ${ }^{[18]}$ it has not been until the beginning of this century when eutectic mixtures started to become popular for the scientific community. ${ }^{[19]}$ Deep eutectic solvents ${ }^{[20]}$ (DES) are formed from an eutectic mixture of two or more solids which are liquid at nearly room temperature (Table 1).

\begin{tabular}{|c|c|c|c|c|c|c|c|}
\hline DES & Proportion ${ }^{[a]}$ & $\mathrm{T}\left({ }^{\circ} \mathrm{C}\right)^{[\mathrm{b}]}$ & Density $\left(\mathrm{g} / \mathrm{cm}^{3}\right)^{[c]}$ & Viscosity (cP) & Conductivity (mS/cm) & Biodegradability ${ }^{[d]}(\%)$ & Preparation ${ }^{\left[{ }^{e]}\right.} \mathrm{T}\left({ }^{\circ} \mathrm{C}\right)$ \\
\hline ChCl-Urea & $1: 2$ & 12 & 1.25 & $750\left(25^{\circ} \mathrm{C}\right)$ & $0.199\left(40^{\circ} \mathrm{C}\right)$ & 97.1 & 75 \\
\hline ChCl-Glycerol & $1: 2$ & -40 & 1.18 & $376\left(20^{\circ} \mathrm{C}\right)$ & $1.05\left(20^{\circ} \mathrm{C}\right)$ & 95.9 & 100 \\
\hline ChCl-Glucose & $1: 2$ & 14 & $1.21\left(85^{\circ} \mathrm{C}\right)$ & $8045.1\left(25^{\circ} \mathrm{C}\right)$ & & 82.0 & 80 \\
\hline ChCl-Malonic acid & $1: 2$ & 10 & 1.25 & $1124\left(25^{\circ} \mathrm{C}\right)$ & 0.36 & 76.3 & 100 \\
\hline ChCl-Tartaric acid & $1: 2$ & 47 & $1.27\left(30^{\circ} \mathrm{C}\right)$ & $66441\left(30^{\circ} \mathrm{C}\right)$ & $0.014\left(30^{\circ} \mathrm{C}\right)$ & 84.6 & 100 \\
\hline ChCl-Citric acid & $1: 2$ & 69 & $1.33\left(30^{\circ} \mathrm{C}\right)$ & $289\left(75^{\circ} \mathrm{C}\right)$ & $0.018\left(30^{\circ} \mathrm{C}\right)$ & 81.6 & 100 \\
\hline ChCl-p-TsOH & 1:1 & 27 & $1.21\left(30^{\circ} \mathrm{C}\right)$ & $183\left(30^{\circ} \mathrm{C}\right)$ & $0.04\left(30^{\circ} \mathrm{C}\right)$ & 80.4 & 120 \\
\hline $\mathrm{ChCl}-\mathrm{ZnCl}_{2}$ & 1:2 & 24 & & $8500\left(25^{\circ} \mathrm{C}\right)$ & $0.06(42 \stackrel{\circ}{\circ})$ & & 100 \\
\hline $\mathrm{ChCl}-\mathrm{SnCl}_{2}$ & $1: 2$ & 37 & & & & & 100 \\
\hline $\mathrm{ChCl}-\mathrm{FeCl}_{3}$ & 1:2 & 65 & & & & & 100 \\
\hline Tartaric acid-DMU & $3: 7$ & 70 & & & & & 90 \\
\hline Citric acid-DMU & $2: 3$ & 75 & & & & & 90 \\
\hline L-Carnitine-Urea & $2: 3$ & 74 & & & & & 80 \\
\hline L-Proline-Oxalic acid & $1: 1$ & -14.5 & 1.35 & $12000\left(27^{\circ} \mathrm{C}\right)$ & & & 80 \\
\hline
\end{tabular}

[a] Molar ratio. [b] Melting point or glass transition temperature. [c] Measured at $25 \stackrel{\circ}{\circ}$, otherwise stated. [d] 28 days Closed Bottle Test, see reference [26b]. [e] DESs are prepared by mixing both components in the appropriate ratio and stirred at the corresponding temperature until formation of homogeneous clear liquid; no further purification is needed. 
They are usually formed by Lewis or Brønsted acids and bases which can contain a variety of anionic and/or cationic species. Some of these mixtures do not show a strict eutectic point (melting point) but a glass transition temperature point, and therefore they are also called low melting mixtures ${ }^{[21]}$ or lowtransition-temperature mixtures. ${ }^{[22]}$ Even the initial restriction of being formed by a mixture of only solids, was overcome by the use of liquids with melting points nearly room temperature, ${ }^{[23]}$ such as ethylene glycol or glycerol (gly). Although from the aforementioned definition of DES the advantage of these mixtures over common organic solvents cannot clearly seen, they have incredibly high potential to replace them. In all cases, their vapor pressure are negligible, but when the typical DES are listed (choline chloride, natural amino acids as Lewis-Brønsted bases or urea, resorcinol, natural carboxylic acids or polyalcohols as Brønsted acids) it is clearly shown that they come from renewable sources. In the case of choline chloride $(\mathrm{ChCl})$, an additive in chicken food for accelerating growth, its industrial production from trimethylamine, hydrochloric acid and ethylene oxide in a continuous, single-stream process is very cheap, simple and mass-produced. The toxicity of these natural deep eutectic solvents ${ }^{[24]}$ is inexistent or very low. ${ }^{[25]}$ On the contrary, their biodegradability is extraordinarily high. ${ }^{[26]}$ Moreover, the atom economy of the final formation of DES is the highest one, since all initial components are included in the final mixture (Table 1). All these facts make their ecological footprint minimum. Finally, it should be pointed out that the high solubility of DES in water enables a very simple work-up of the reaction: the addition of water dissolves the DES and the organic products precipitate or appears as a water insoluble layer, avoiding the typical organic solvent extraction at the end of the reaction. The evaporation of water from the aqueous layer allows the recycling of the initial DES.

The polarity of these solvents, usually ranging from 4 $\left(\mathrm{CHCl}_{3}\right)$ to higher than 80 (water), is what capacitates the easy solution of many organic and inorganic reagents and catalysts. ${ }^{[27]}$ Moreover, the possibility of microemulsion formation by typical tensioactive compounds ${ }^{[28]}$ or directly, ${ }^{[29]}$ ensures, at least, the partial solubility of less polar organic reagents, which highlights the enormous ability of these mixtures as a possible medium in Organic Synthesis.

An important disadvantage addressed by some researchers arises from the high density and viscosity of the usual DES mixtures. ${ }^{[30]}$ This could be a problem at industrial scale or in continuous flow reactions (Table 1). However, the addition of a new different component, such water, carboxylic acid, inorganic/organic halide, which forms ternary mixtures, has frequently an important and positive impact on the viscosity and density. ${ }^{[31]}$

All the aforementioned facts have made of DES ${ }^{[32]}$ the chosen solvent for many applications, including among others, biotechnology, ${ }^{[33]}$ analytical chemistry, ${ }^{[34]}$ polymerization, ${ }^{[35]}$ extraction and separation processes, ${ }^{[36]}$ nanotechnology, ${ }^{[37]}$ or biomass valorization. ${ }^{[38]}$

This microreview focuses on the efforts made to use DES as solvent in all type of organic reactions. ${ }^{[39]}$ In order to highlight the future possibilities, as well as the less developed areas, this article has been divided firstly according to the role of DES in the reaction, and then according to the reaction type, paying particular attention to the scope of the processes as well as the number of reported examples.

\section{Active DES}

Many organic reactions are catalyzed by acids or bases and these components appear in DES. Thus, these mixtures can be used not only as just a reaction medium but also as a catalytic active species for some reactions, as well as a part of the starting materials. In this section, different transformations where some of the components of the DES have either an intrinsic reagent character or play an important role as acid/base catalyst will be presented.

\subsection{DES Reagents}

Carbohydrates, which are the largest part of all biomass, ${ }^{[40]}$ can be suitable components in eutectic mixtures. On the other hand, the conversion of carbohydrates into useful chemicals is of particular interest. Thus, 5-hydroxymethylfurfural (HMF), a biomass-derived chemical, is considered remarkable due to its potential as a sustainable substitute for petroleum-based building blocks. The use of eutectic mixtures of carbohydrates (i.e. fructose, glucose, sucrose and inulin) with choline chloride (carbohydrate- $\mathrm{ChCl} \mathrm{w} / \mathrm{w}$ ratio from 2:3 to $1: 1$ ) were effective in the transformation of the carbohydrate component into HMF, in the presence of an acidic catalyst [i.e. $\mathrm{CrCl}_{2}$ or $p$-toluenesulfonic acid $(p-\mathrm{TsOH})] .^{[41]}$ More recently, the use of a catalyst based on heteropolyacids $\left(\mathrm{H}_{3} \mathrm{PW}_{12} \mathrm{O}_{40}\right)$ and lysine improved the transformation of fructose into HMF (up to $93 \%$ conversion in 1 $\min ) .{ }^{[42]}$

Urea derivatives are typical constituents of low melting mixtures. In this context, an aldehyde heated in a mixture of choline chloride-urea (1:2 molar ratio) reacted with the urea producing the corresponding geminal diurea (Scheme 1). ${ }^{[43]}$

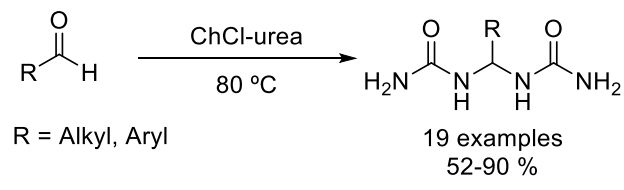

Scheme 1. Synthesis of gem-diureas.

Moreover, $N, N^{\prime}$-dimethylurea (DMU) has been typically employed in the synthesis of several heterocyclic derivatives. Thus, a variety of dihydropyrimidinones were prepared by means of a multicomponent reaction of DMU, aldehydes and ketoesters, in a deep eutectic solvent formed by the same DMU and tartaric acid (Scheme 2). ${ }^{[44]}$ 


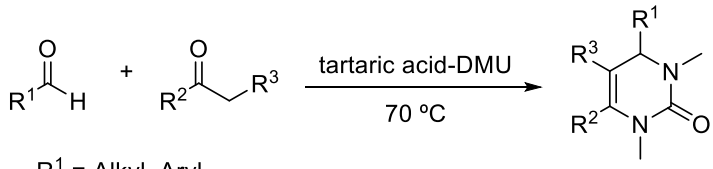

$$
\begin{aligned}
& \mathrm{R}^{1}=\text { Alkyl, Aryl } \\
& \mathrm{R}^{2}=\text { Aryl, Aryl } \\
& \mathrm{R}^{3}=\mathrm{COMe}, \mathrm{CO}_{2} \mathrm{R}
\end{aligned}
$$

Scheme 2. Synthesis of dihydropyrimidinones.

Furthermore, phenacyl bromides reacted with the urea component of a DES (ChCl-urea, 1:2) producing the corresponding aminooxazole derivatives (Scheme 3), the DES being possible to be recycled up to five times after addition of water and extraction of the product with dichloromethane. ${ }^{[45]}$ The reaction under ultrasound irradiation gave better results in shorter times than when using conventional heating.

Different mixtures of choline chloride $(\mathrm{ChCl})$ and itaconic acid $(\mathrm{IA})$ were prepared as DES, but in the proper ratio $(\mathrm{ChCl}-\mathrm{IA}$, from $1.5: 1$ to $2: 1$ ) itaconic acid tended to polymerize. Moreover, the copolymerization in the presence of $N, N$ methylenebisacrylamide underwent faster in DES than in water and the obtained product had higher cross-link density. ${ }^{[46]}$ The formation of poly(octanediol-co-citrate) was performed in a mixture of 1,8-octanediol and lidocaine (3:1 molar ratio), as DES, citric acid being employed as initiator of the polymerization reaction. ${ }^{[47]}$ The process ended up with the formation of an elastomer containing lidocaine, which can be employed as a drug-delivery system.

Scheme 3. Synthesis of aminooxazoles.

$$
\begin{gathered}
\begin{array}{c}
65^{\circ} \mathrm{C} \text { or } \\
\text { ultrasounds }\left(35^{\circ} \mathrm{C}\right)
\end{array} \\
\text { Conv. heating }\left(65^{\circ} \mathrm{C}\right) \\
\begin{array}{c}
\text { ChCl-Urea } \\
4 \text { examples } \\
51-69 \%
\end{array}
\end{gathered}
$$$$
\text { Ultrasounds }\left(35^{\circ} \mathrm{C}\right) \quad \begin{aligned}
& 51-69 \% \\
& 79-90 \%
\end{aligned}
$$

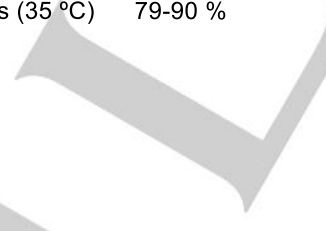

\subsection{DES Catalyst}

\subsubsection{Red-Ox Reactions}

Regarding oxidations, an efficient catalytic system for the oxidation of alcohols with molecular oxygen as terminal oxidant was described employing immobilized TEMPO on a DES (TEMPO-ammonium bromide-urea in ratio 2:1, Figure 2).

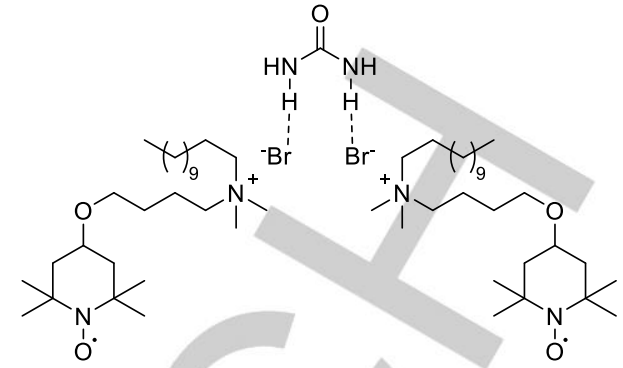

Figure 2. Structure of DES-supported TEMPO.

Different benzylic, allylic and alkylic primary and secondary alcohols were oxidized in the DES-TEMPO combination in an oxygen atmosphere, and in the presence of iron nitrate, to give the corresponding carbonyl compounds with excellent conversions and selectivities (Scheme 4). ${ }^{[48]}$ Both iron and TEMPO species are involved in the reaction mechanism. The recyclability of DES-TEMPO mixture was proved by simple distillation of the product, although addition of fresh iron precursor was required after each run.

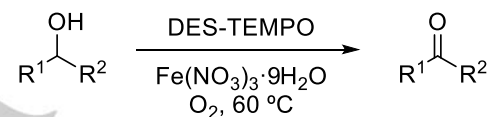

$$
\begin{aligned}
& \mathrm{R}^{1}=\text { Alkyl, Arylmethyl } 21 \text { examples } \\
& \mathrm{R}^{2}=\mathrm{H} \text {, Alkyl } \quad 80-99 \%
\end{aligned}
$$

Scheme 4. Oxidation of alcohols to carbonyl compounds.

The $\alpha$-chlorination of ketones can be easily achieved with 1,3-dichloro-5,5-dimethylhydantoin (DCDMH) in organic solvents. In contrast, a $\alpha, \alpha$-dichlorinated product was exclusively obtained, with DCDMH, when the reaction was carried out in a DES formed by an equimolecular mixture of choline chloride and $p$ toluenesulfonic acid $(p-\mathrm{TsOH})$ and a small amount of acetonitrile $(6 \% \mathrm{w} / \mathrm{w}) \cdot{ }^{\left[{ }^{[9]}\right.}$ Moreover, if a mixture of TBAF $\cdot 3 \mathrm{H}_{2} \mathrm{O}$ and $\mathrm{ZnF}_{2}$ was added to the reaction medium, the formed chlorinated acetophenone underwent nucleophilic substitution giving directly the corresponding a-fluoroacetophenones in a one-pot methodology (Scheme 5). ${ }^{[50]}$

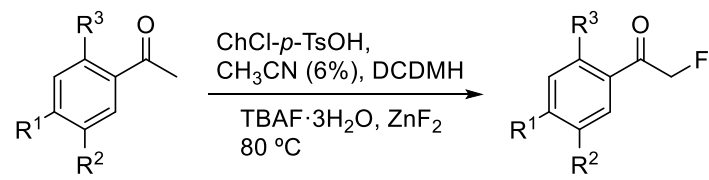

$$
\begin{array}{lc}
\mathrm{R}^{1}=\mathrm{H}, \mathrm{Me}, \mathrm{OMe}, \mathrm{Cl}, \mathrm{Br} & 11 \text { examples } \\
\mathrm{R}^{2}=\mathrm{H}, \mathrm{OMe} & 32-80 \%
\end{array}
$$$$
\mathrm{R}^{3}=\mathrm{H}, \mathrm{Br}
$$ 


\subsubsection{Esterification-type Reactions}

Lewis or Brønsted catalyzed esterification between carboxylic acids and alcohols is a well-established protocol in organic synthesis, but some difficulties are found when using acids or alcohols with carbon chains longer than $\mathrm{C}_{10}$. The DES formed by choline chloride $(\mathrm{ChCl})$ and zinc chloride, in a molar ratio $1: 2$, revealed as a catalytic reaction medium for the esterification of long chain aliphatic carboxylic acids with long chain alcohols, both between $\mathrm{C}_{8}-\mathrm{C}_{22}$ (Scheme 6). ${ }^{[51]}$ The recyclability of the catalytic DES in the esterification of octanoic acid and cetyl alcohol was proved up to six times without loss of activity. The same catalytic DES $\left(\mathrm{ChCl}-\mathrm{ZnCl}_{2}, 1: 2\right)$ was successfully employed for the acetylation of monosaccharides. ${ }^{[52]}$ In contrast, DES formed from trimethylcyclohexyl ammonium methanesulfonate and $p$ toluenesulfonic acid (TCyAMsO-p-TsOH, 1:1 molar ratio) has been described as a good catalytic reaction medium for smaller alcohols (less than $\mathrm{C}_{8}$ ). Thus, aliphatic and aromatic carboxylic acids were heated $\left(60-80{ }^{\circ} \mathrm{C}\right)$ in the mixture TCyAMsO-p-TsOH (1:1) during 2-17 $\mathrm{h}$ producing the corresponding esters with yields ranging from 16 to $97 \% .{ }^{[53]}$ Based on the same idea, a mixture of urea and $\mathrm{ZnCl}_{2}$ (4:1 molar ratio) was active as catalytic medium in the glycolysis of poly(ethyleneterephthalate) by transesterification with ethylene glycol. ${ }^{[54]}$

\subsubsection{Condensation-mediated Processes}

The reaction of indoles (i.e. indole, 1-methylindole, 2methylindole and 5-bromoindole) with aromatic and aliphatic aldehydes in the DES ChCl-SnCl ${ }_{2}$ (1:2) produced the corresponding bis(indol-3-yl)methane derivatives with yields ranging from 64 to $97 \% .{ }^{[56]}$ The outcome of the reaction at room temperature was improved by the addition of polyethylene glycol-200 (PEG-200) as a third partner of the solvent mixture, in a volume ratio 1:3 (DES to PEG-200). The same transformation was described in the mixture $N, N$-dimethylurea-citric acid $(3: 2$ ratio) at $100{ }^{\circ} \mathrm{C}$, with slightly lower yields than with the solvent ChCl-SnCl 2 -PEG-200. [57] Derivatives of arsindoline A and B (Figure 3) were prepared by means of the same condensation reaction using a catalytic DES prepared from $N, N$-dimethylurea and tartaric acid (7:3 molar ratio). ${ }^{[58]}$

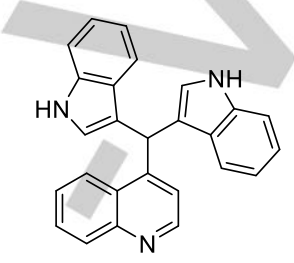

arsindoline A

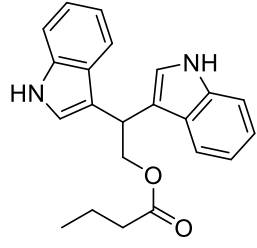

arsindoline B
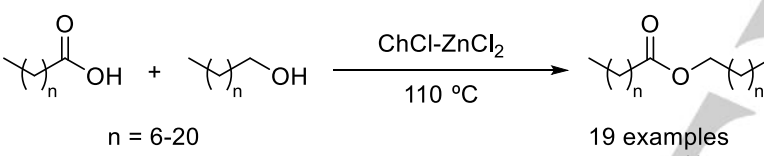
93-99\%

Scheme 6. Esterification of carboxylic acids with alcohols.

Anilines reacted with formic acid or trimethyl orthoformate in a deep eutectic solvent giving the corresponding formanilides or diarylamidines depending on the ratio aniline/formic acid (Scheme 7). The solvent was formed employing choline chloride and tin chloride (1:2 molar ratio), and after the reaction the products were easily extracted with an organic solvent. ${ }^{[55]}$

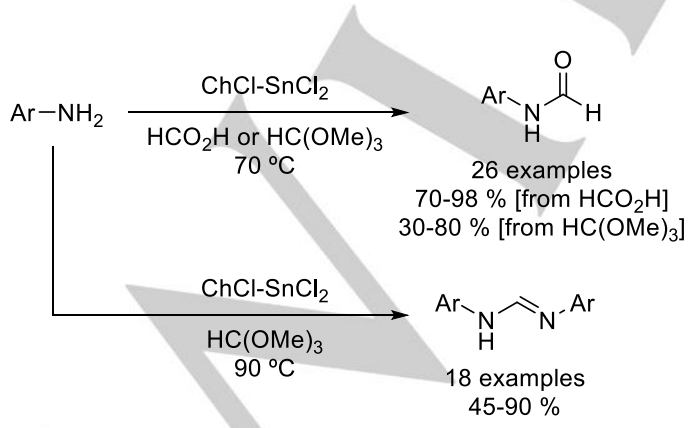

Scheme 7. Esterification of carboxylic acids with alcohols.
Figure 3. Arsindoline A and arsindoline B.

The synthesis of xanthene derivatives was performed in different DES based on choline chloride. The best combination was with zinc chloride ( $\mathrm{ChCl}-\mathrm{ZnCl}_{2}, 1: 2$ molar ratio), producing a reaction medium that catalysed the condensation reaction of aromatic aldehydes with 1,3-cyclohexanediones (Scheme 8). ${ }^{[59]}$ The same transformation was also reported in a mixture of $N, N$ dimethylurea and citric acid (3:2 mass ratio, Scheme 8$)$. For the latest, recyclability was studied observing a small loss of activity after 6 cycles. ${ }^{[60]}$

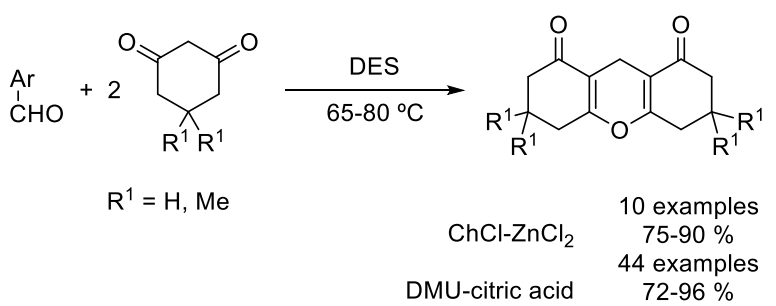

Scheme 8. Synthesis of xanthene derivatives.

Other heterocycles were prepared by condensation reactions in a catalytic DES formed by an acidic component. Thus, the mixture DMU-citric acid was employed in the preparation of quinolines (Scheme 9) and in the synthesis of 2,4,5-triarylimidazoles (Scheme 10). ${ }^{[57]}$ 


$$
\begin{aligned}
& \mathrm{R}^{1}=\mathrm{H}, \mathrm{Cl} \\
& \mathrm{R}^{2}=\mathrm{Alkyl} \\
& \mathrm{R}^{1}=\text { Alkyl, COAlkyl, } \mathrm{CO}_{2} \mathrm{Et}
\end{aligned}
$$

Scheme 9. Synthesis of quinoline derivatives.

$$
\mathrm{Ar}-\mathrm{CHO}+\prod_{\mathrm{O}}^{\mathrm{O}} \mathrm{Ph} \frac{\mathrm{DMU} \text {-citric acid }}{100^{\circ} \mathrm{C}} \overbrace{\substack{5 \text { examples } \\ 86-92 \%}}^{\mathrm{O}}
$$

Scheme 10. Synthesis of imidazole derivatives.

$N$-Arylpyrroles were prepared by reaction of anilines and 2,5-dimethoxytetrahydrofuran in a catalytic reaction media formed by choline chloride and L-tartaric acid (Scheme 11). ${ }^{[61]}$

$$
\mathrm{Ar}-\mathrm{NH}_{2}+\underbrace{\mathrm{OMe}}_{\mathrm{OMe}} \frac{\text { ChCl-tartaric acid }}{90^{\circ} \mathrm{C}}
$$

Scheme 11. Synthesis of pyrrole derivatives

The ring opening of 1,3-propanesultone with different tertiary amines allowed the synthesis of sulfobetaines, which were employed in the preparation of deep eutectic solvents in combination with (1S)-10-camphorsulfonic acid. Among them, the DES prepared from $\mathrm{N}$-cyclohexyl- $\mathrm{N}, \mathrm{N}$-dimethyl-3-ammonio1-propanesulfonate and the sulfonic acid (3:2 molar ratio) was effective as catalytic reaction medium in the aldol condensation of benzaldehyde and acetophenone giving chalcone in $70 \%$ yield. ${ }^{[62]}$

\subsubsection{Multicomponent Reactions}

Multicomponent Reactions (MCRs) have become a very important tool in organic synthesis since three or more starting materials react to form the corresponding product, usually with a high atom economy. Deep eutectic solvents have been used as sustainable media, as well as catalysts, in different multicomponent reactions, with the most successful constituent being choline chloride $(\mathrm{ChCl})$. In particular, deep eutectic solvents based on choline chloride and metal chlorides have been used in the synthesis of dihydropyrimidinone derivatives through the Biginelli reaction, ${ }^{[63]}$ as well as in the preparation of functionalized amines, such as $\beta$-aminoketones ${ }^{[64]}$ and $\alpha$ - aminophosphonates ${ }^{[65]}$ through multicomponent reactions. Thus, the Biginelli reaction using a mixture of choline chloride-tin(II) chloride (1:2 molar ratio) as catalyst and reaction media has been used in the synthesis of 3,4-dihydropyrimidin-2(1H)-one derivatives (Scheme 12). A broad range of 1,3-dicarbonyl compounds as well as both aromatic and aliphatic aldehydes reacted with urea at $110^{\circ} \mathrm{C}$ to give, after very short reaction times, the corresponding heterocyclic compounds in good to excellent yields. Interestingly, the synthesized products were isolated pure by a simple extraction from the reaction media and the DES could be recycled and reused for four cycles without any loss of activity.

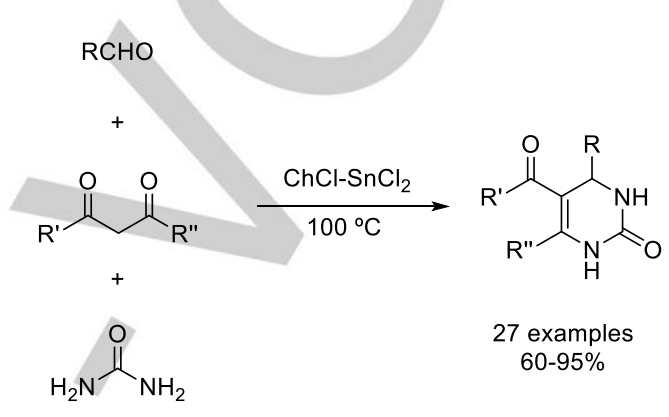

$\mathrm{R}=\mathrm{Aryl}, i-\mathrm{Pr}$

$\mathrm{R}^{\prime}, \mathrm{R}^{\prime \prime}=\mathrm{Alkyl}$, Aryl, OAlkyl NHAr,

Scheme 12. Biginelli reaction.

The mixture Choline chloride-zinc(II) chloride has been recently used as catalyst (15 mol\%) in the solvent-free one-pot three component Kabachnik-Fields reaction for the preparation of $\alpha$-aminophosphonates. ${ }^{[65]}$ The reaction, which under conventional conditions requires toxic metal catalysts, long reaction times, and the foul smelling triethyl phosphite as reagent, allows the preparation of the target compounds in good yields and very short reaction times at room temperature, as depicted in Scheme 13. Furthermore, the DES was easily recycled and reused for five cycles. A dual activation of the electrophile by the Lewis acid $\mathrm{ZnCl}_{2}$ and the nucleophile by the in situ formed Lewis base $\mathrm{ChZnCl}_{3}$ has also been proposed.

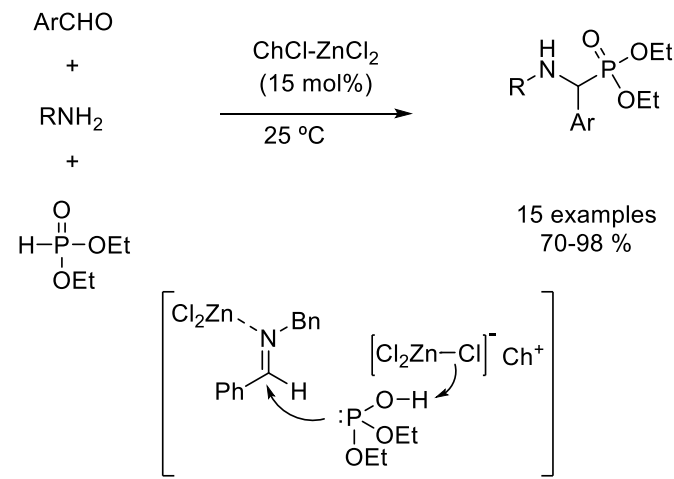

Scheme 13. Kabachnik-Fields reaction. 
DESs obtained by mixing in the appropriate molar ratio $\mathrm{ChCl}$ with organic Brønsted acids, such as malonic acid, ${ }^{[66]}$ oxalic acid, ${ }^{[67]}$ and $p$-TSOH, ${ }^{[68]}$ have been used as catalyst and reaction media in the synthesis of a wide variety of heterocycles. For instance, a one-pot high-yielding four-component synthesis of substituted pyrroles, by reaction of aromatic aldehydes, amines, 1,3-dicarbonyl compounds, and nitromethane in a 1:1 molar mixture of $\mathrm{ChCl}$ and malonic acid at $80{ }^{\circ} \mathrm{C},{ }^{[66]}$ has been very recently reported (Scheme 14).

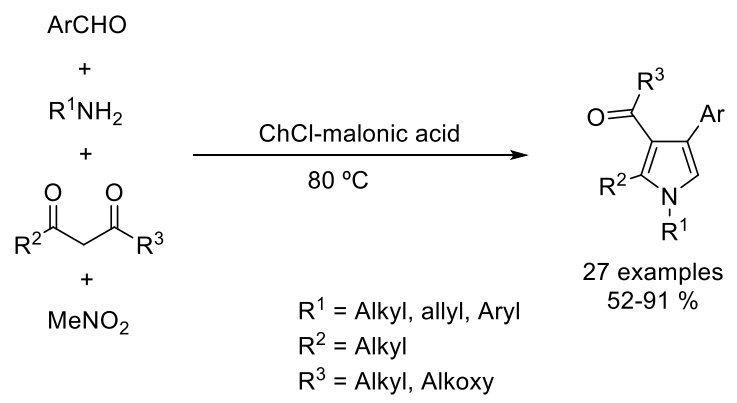

\footnotetext{
Method comparison for $\mathrm{Ar}=\mathbf{R}^{\mathbf{1}}=\mathbf{P h}, \mathbf{R}^{2}=\mathbf{R}^{3}=\mathbf{M e}$ ChCl-malonic acid, $80{ }^{\circ} \mathrm{C}, 90 \%$ [ref. 66] $\mathrm{CoFe}_{2} \mathrm{O}_{4} @ \mathrm{SiO}_{2}-\mathrm{NH}_{2}-\mathrm{Mo}(\mathrm{acac})_{2}(1 \mathrm{~mol} \%), \mathrm{MeNO}_{2}, 90 \%$ [ref. 69a] $\mathrm{I}_{2}(10 \mathrm{~mol} \%), \mathrm{MeNO}_{2}, 90^{\circ} \mathrm{C}, 85 \%$ [ref. $69 \mathrm{~b}$ ] Gluconic acid aqueous solution, $100{ }^{\circ} \mathrm{C}, 87 \%$ [ref. 69c] [bmim] $\mathrm{HSO}_{4}(20 \mathrm{~mol} \%), \mathrm{MeNO}_{2}, 90^{\circ} \mathrm{C}, 90 \%$ [ref. $69 \mathrm{~d}$ ]
}

Scheme 14. Synthesis of functionalized pyrroles.

As depicted in Scheme 14 for the synthesis of 1-(2-methyl1,4-diphenyl-1H-pyrrol-3-yl)ethan-1-one, this methodology affords yields as high as the best previously reported systems, ${ }^{[69]}$ but in a shorter reaction times and avoiding the use of the nitromethane as reaction media. Some drawbacks of the methodology were that alkyl aldehydes afforded inseparable complex reaction mixtures. The recyclability of the DES (up to five reaction runs) and its synergistic effect on the reaction outcome has also been demonstrated. [66]

Synthetic and natural spirooxindole derivatives are very important compounds due to their biological activity and applications in pharmaceutical chemistry. ${ }^{[70]}$ Among the different routes to synthesize spirooxindoles, ${ }^{[71]}$ those starting from isatin ${ }^{[72]}$ have been widely studied. Very recently, L-proline has been used, in combination with oxalic acid dihydrate (1:1 molar ratio), as a successful and recyclable low transition temperature solvent and hydrogen-bonding catalyst for the room temperature synthesis of spirooxindoles by a three component reaction of isatin, malononitrile or ethyl acetate, and 1,3-dicarbonyl compounds. ${ }^{[73]}$ This methodology worked well in short reaction times (30-70 $\mathrm{min}$ ) with a wide variety of 5 - and $\mathrm{N}$-substituted isatins, although only 6-member ring 1,3-dicarbonyl compounds, such as dimedone, have been reported as nucleophiles (see Scheme 15). This represents a significant limitation of this methodology since other similar three-component syntheses of spirooxindole derivatives from isatin allow the use of a wider array of nucleophiles. ${ }^{[74]}$ Furthermore, regarding reusability, the solvent can easily be recovered from the reaction mixture, although a noticeable decrease in yield is observed in the fifth cycle.

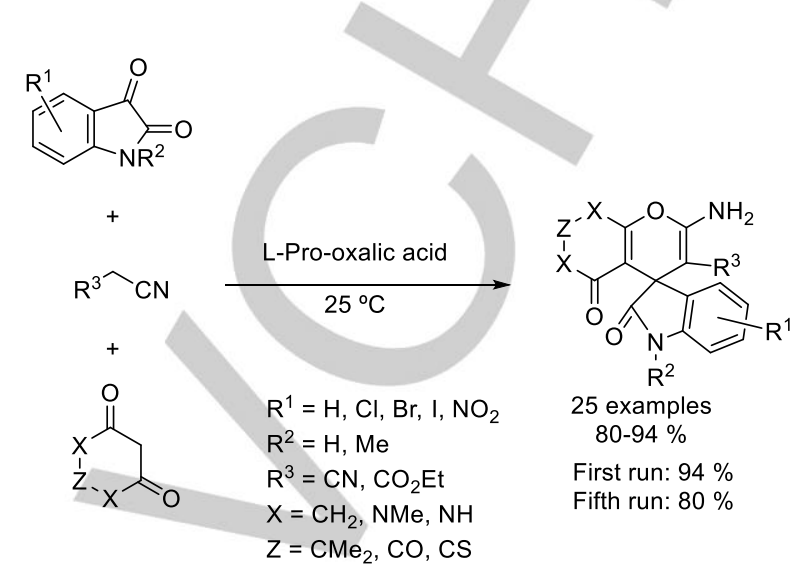

Scheme 15. Multicomponent synthesis of spirooxindoles.

Finally, The synthesis of tri- and tetrasubstituted imidazoles has been achieved by condensation reaction of benzyl, aldehydes and ammonium acetate in acidic DES, such as $\mathrm{ChCl}-\mathrm{ZnCl}_{2}{ }^{[75 a]}$ (1:2 molar ratio) or ChCl-oxalic acid ${ }^{[75 b]}$ (1:1 molar ratio), at $100{ }^{\circ} \mathrm{C}$. The reaction was limited at aromatic aldehydes with yields ranging from 52 to $95 \%$ (28 examples). Only for the oxalic mixture the reusability was demonstrated.

\subsubsection{Cyclization Reactions}

A very interesting regiospecific one-pot Fischer indole synthesis has been reported using a 1:2 molar ratio mixture of choline chloride- $\mathrm{ZnCl}_{2}$ as stoichiometric Lewis acid reagent. ${ }^{[76]}$ As usually in reactions where DES reagents and/or solvents are involved, an easy product isolation could be performed. In this particular case, since the DES has very little or no vapour pressure, a direct vacuum sublimation of the product from the reaction mixture afforded the corresponding 2,3-disubstituted indoles in good isolated yields (Scheme 16).

An interesting finding was related with the actual species present in the $\mathrm{DES} \mathrm{ChCl}-\mathrm{ZnCl}_{2}$ reagent, which have been identified by $\mathrm{FAB}$ mass spectrometry as $\left(\mathrm{Zn}_{2} \mathrm{Cl}_{5}\right)^{-},\left(\mathrm{ZnCl}_{3}\right)^{-}$, and $\left(\mathrm{Zn}_{3} \mathrm{Cl}_{7}\right)^{-}$. These species would play different roles in the Fischer synthesis, such as, Lewis base $\left[\left(\mathrm{Zn}_{2} \mathrm{Cl}_{5}\right)^{-}\right]$and Brønsted base $\left[\left(\mathrm{ZnCl}_{3}\right)^{-}\right]$. Regarding the regioselectivy observed for nonsymmetrical ketones, a mechanism involving the formation of the most substituted enamine intermediate has been proposed (Scheme 16). Since the Fischer indole reaction generates 1 equiv. of ammonia, a marked decrease in the efficiency of the process is observed when trying to reuse the DES reagent, probably due to the deactivation of the zinc salt after coordination with the in situ formed ammonia. Another handicap was the poor ketone scope shown by this methodology. 


$$
\begin{array}{ll}
\mathrm{R}^{1}=\mathrm{H}, 2,5-\mathrm{Cl}_{2}, 4-\mathrm{Cl}_{2}, 2-\mathrm{Me} & \text { 16 examples } \\
\mathrm{R}^{2}, \mathrm{R}^{3}=\mathrm{Me}, \mathrm{Et},\left(\mathrm{CH}_{2}\right)_{4} & \text { 48-88\% }
\end{array}
$$

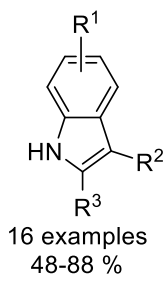

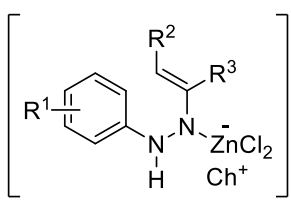

Scheme 16. Fischer indole synthesis.

Diels-Alder reactions are among the most studied and useful C-C bond forming processes in organic chemistry. Already in 2002, the efficiency of mixtures composed of choline chloride-zinc or tin chlorides (1:2 molar ratio) as solvents and Lewis acid catalysts was reported for the reaction between different dienes (2,3-dimethylbuta-1,3-diene, isoprene, 1,3cyclohexadiene, and cyclopentadiene) and acrylaldehyde, but-3en-2-one, methyl acrylate, and methacrylaldehyde as dienophiles. ${ }^{[77]}$ As depicted in Scheme 17, a high endo selectivity was obtained (up to 97/3), something typical for Lewis acid-catalyzed reactions. In comparison to conventional organic solvents, faster conversions were observed.

Interestingly, the presence of water did not affect the yield or the selectivity of the process but it reduced the viscosity of the DES allowing an effective stirring of the reaction. In addition, since the products of the cycloadditions were not soluble in the DES they were easily isolated by decanting or with the help of a pipette. The DES was easily separated and reused at least five times with no noticeable drop in activity. Mass spectroscopic analysis of the recycled medium suggested that the $\mathrm{ChCl}$ may have slowly reacted with the dienophiles through a conjugate addition reaction.

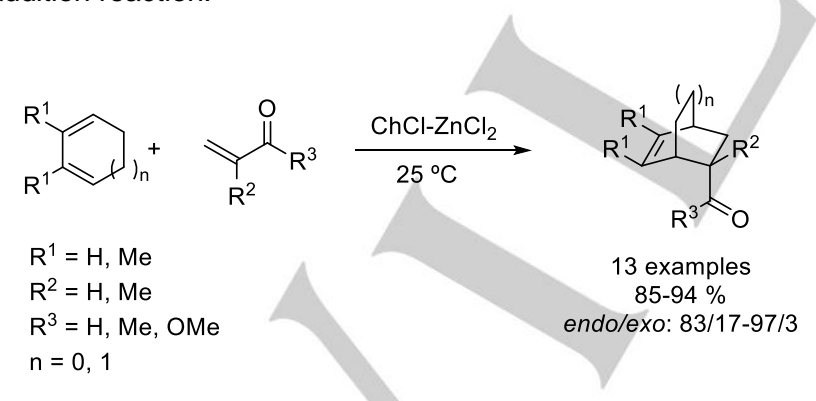

Scheme 17. DES-catalyzed Diels-Alder reaction.

The Diels-Alder reaction between cyclopentadiene and alkyl acrylates has been studied using as reaction media mixtures of carbohydrates, sugar alcohols or citric acid with urea and inorganic salts. ${ }^{[78]}$ Particularly, a 70/20/10 mixture of sorbitol, dimethylurea, and ammonium chloride has been shown to efficiently catalyzed the cycloaddition with good endo selectivity. Unfortunately, no significant stereoinduction of the solvent on the reaction was detected.

\subsubsection{Miscellaneous Reactions}

Deep eutectic mixtures have also been used in different carbon-carbon and carbon-heteroatom bond forming processes. Among them, the beneficial activating effects of DES have been demonstrated in different conjugate additions, such as the thiaMichael addition to $\alpha, \beta$-unsaturated carbonyl compounds, ${ }^{[79,80]}$ and the addition of activated methylene derivatives to chalcones, as depicted in Figure 4 for representative examples.

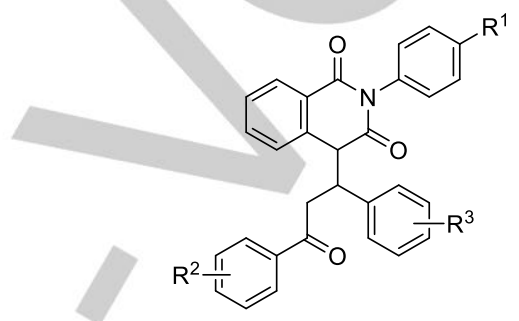

$$
\begin{aligned}
& R^{1}=H, R^{2}=H, R^{3}=H, 88 \% \\
& R^{1}=H, R^{2}=H, R^{3}=4-M e, 82 \% \\
& R^{1}=H, R^{2}=4-M e, R^{3}=4-M e, 73 \% \\
& R^{1}=H, R^{2}=4-B r, R^{3}=4-M e, 90 \% \\
& R^{1}=4-C l, R^{2}=3-M e, R^{3}=4-M e, 76 \%
\end{aligned}
$$

Figure 4. Michael addition of homophthalimides with chalcones

For instance, the mixture L-(+)-tartaric acid-DMPU (3:7 molar ratio) has been employed very recently as solvent and catalyst for the Michael addition of a variety of $\mathrm{N}$ arylhomophthalimides and chalcones. ${ }^{[80 b]}$ This acidic melt system ( $\mathrm{pH}$ in water 3.7 ) allowed to perform the conjugate addition at $70 \stackrel{\circ}{\circ}$ to yield the corresponding adducts in good to excellent yields (73-92 \%; 13 examples). The reaction was highly diastereoselective and all products were obtained as a single isomer. However, as expected, no stereo-induction was detected when using chiral DES. On the other hand, and based on the acid character of the melt, a mechanistic proposal for the reaction involving multiple key activation roles of the solvent (Brønsted acid and hydrogen-bonding formation) as well as a plausible structure of the melt has been reported based on IR and ${ }^{1} \mathrm{H}-\mathrm{NMR}$ analyses (Figure 5).

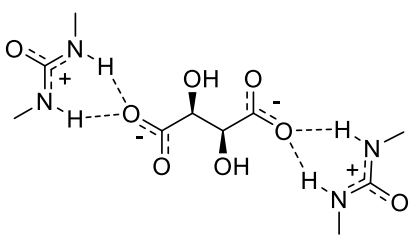

Figure 5. Plausible structure of the L-(+)-tartaric acid/dimethyl urea melt. 
Substoichiometric amounts (40 mol\%) of a 1:2 molar ratio mixture of choline chloride-tin(II) chloride has been employed as catalyst for the regioselective ring-opening of epoxides with different nucleophiles, such as thiols, aniline derivatives, trimethylsilyl cyanide, trimethylsilyl azide, and methanol (48 examples; $68-97 \%$ yield). ${ }^{[81]}$ The reactions, which were carried out at room temperature for 10 to $180 \mathrm{~min}$, afforded the corresponding functionalized alcohols in high yields after a very easy work-up procedure (Scheme 18). This methodology allowed the recovery of the DES by precipitation after addition of diethyl ether to the reaction mixture. The recovered melt was reused in the preparation of 1-phenoxy-3-(phenylthio)propan-2ol without losing its activity for four runs.

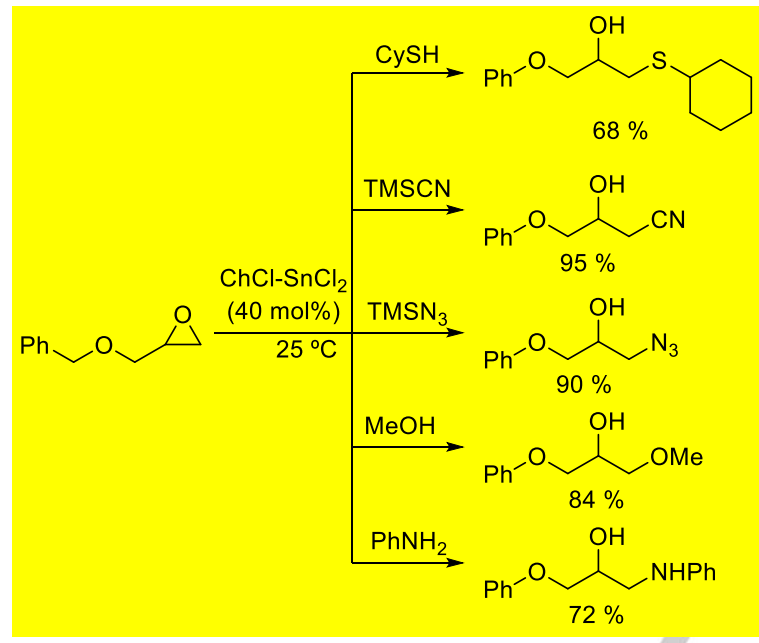

Scheme 18. Ring-opening of epoxides.

Choline chloride-zinc(II) chloride has been recently studied as solvent and catalyst to perform different functional group transformations. For instance, the protection of aliphatic and aromatic aldehydes with 1,2-, 1.3-, and 1,4-diols at room temperature, transcurred in 10 to 20 hours when using $\mathrm{ChCl}$ $\mathrm{ZnCl}_{2}$ (1:2 molar ratio) as Lewis acid catalyst. ${ }^{[82]}$ The same DES has been effectively used, in this case acting as solvent as well, in a one-pot transformation of aromatic- and $\alpha, \beta$-unsaturated aldehydes to amides through a Beckmann rearrangement, as well as in the hydrolysis of nitriles to amides (Scheme 19). ${ }^{[83]}$ Concerning recyclability and reusability, the DES was recycled for five times but with a marked decrease in the product yield (98 to $82 \%)$.

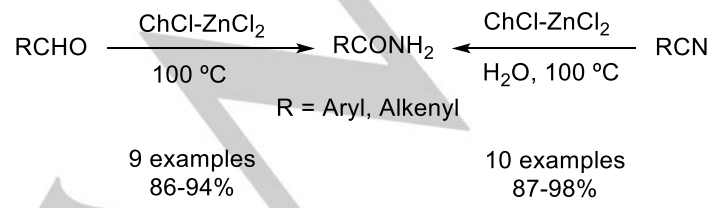

Scheme 19. Synthesis of amides from aldehydes or nitriles.
Pillar[n]arenes are supramolecular macrocyclic hosts with important applications in supramolecular chemistry. ${ }^{[84]} \mathrm{A}$ direct method to prepare this type of compounds involved a condensation reaction between 1,4-dialkoxybenzenes and paraformaldehyde catalyzed by acids. Very recently, it has been described a selective condensation of 1,4-dialkoxybenzenes with paraformaldehyde catalyzed by choline chloride- $\mathrm{FeCl}_{3} \mathrm{DES}$ (15 mol\%) in $\mathrm{CH}_{2} \mathrm{Cl}_{2}$ at room temperature to synthesize pillar[5]and pillar[6]arenes (Scheme 20). ${ }^{[85]}$
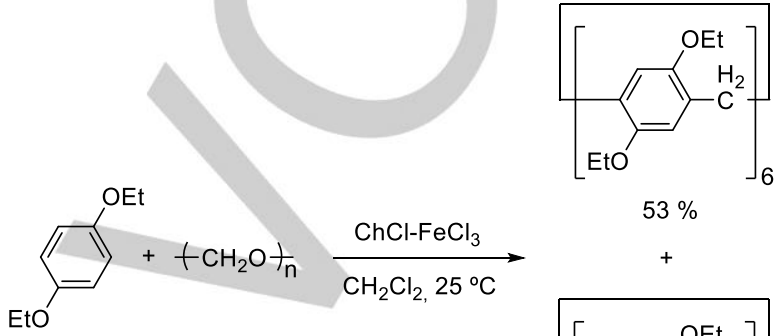

$53 \%$

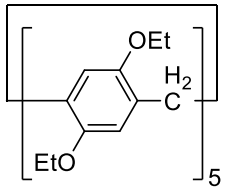

$35 \%$

Scheme 20. Synthesis of pillar[n]arenes.

Although the reported isolated yields for the synthesized macrocyclic hosts were modest, as depicted in Scheme 20 for the synthesis from 1,4-dimethoxybenzene, this work expanded the scope of DES towards supramolecular synthesis. Experimental and room-temperature X-band Electron Spin Resonance (ESR) studies have demonstrated that free radicals take part in the macrocyclization as intermediates.

The dehydration conversion of fructose to 5hydroxymethylfurfural has been studied using different acidic DES, such as choline chloride-citric acid, ${ }^{[86 a]}$ betaine hydrochloride-glycerol, ${ }^{[86 \mathrm{~b}]}$ and choline chloride-p-toluenesulfonic acid, ${ }^{[86 c]}$ obtaining in all cases high yields (84-96\%). In the first two cases the recyclability of DES was studied during 8 and 7 cycles, respectively, practically maintaining their initial activity.

\section{Innocent DES}

In this chapter, reactions in which the role of DES medium is not clearly identified, therefore being categorized as "innocent" DES medium, will be introduced. However, this only means that DES medium does not play a clear role as acid/base catalyst or reagent, since in many examples the chosen medium is of great importance in order to achieve a successful reaction. 


\subsection{Red-Ox Reactions}

Benzyl alcohols have been oxidized to their corresponding aldehydes in a fast way employing $N$-bromosuccinimide (NBS) as oxidant in $\mathrm{ChCl}$-urea as DES (Scheme 21). ${ }^{[87]}$ The formation of any undesirable side product, such as overoxidation to the corresponding carboxylic acid when working with an excess of NBS, was not observed. Secondary benzylic alcohols such as $1-$ phenylethanol underwent selective oxidation to the corresponding acetophenone, with benzyl alcohol remaining untouched with 1 equiv of NBS. The replacement of DES with an organic solvent decreased significantly the obtained yield. In addition, hydrogen peroxide was employed as an oxidant in the transformation of sulfides to sulfoxides, using as DES a combination of $\mathrm{ChCl}$ and $p$-toluenesulfonic acid $(\mathrm{ChCl}-p-\mathrm{TsOH}$, $1: 1)$ at $100{ }^{\circ} \mathrm{C}$, the reusability of the DES being confirmed at a gram-scale synthesis. ${ }^{[8]}$

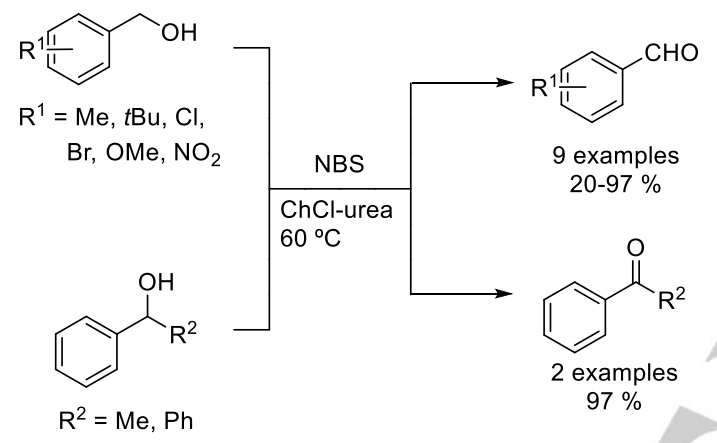

Scheme 21. Oxidation of alcohols.

The use of the DES combination ChCl-urea (10 $\mathrm{mol} \%$ ) in aqueous hydrogen peroxide ( 5 equiv) at room temperature allowed the oxidation of arylboronic acids to their corresponding phenols in up to $15 \mathrm{~min}$ (Scheme 22). ${ }^{[89]}$ Remarkably, the reaction of other arylboronic surrogates such as phenylboronic acid esters or potassium phenyltrifluoroborate, afforded the phenols in high yields, albeit much longer reaction times were required. The recovery involved evaporation of the water after isolation of the product by filtration. The DES was reused without loss of activity in five consecutive runs.

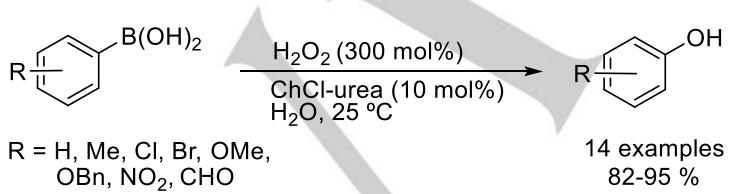

Scheme 22. Oxidation of boronic acids.

The bromination of some aromatic systems has also been achieved in the presence of a DES. Thus, substituted 1aminoanthra-9,10-quinones have been mono- or di-brominated when treated with bromine in $\mathrm{ChCl}$-urea at $50-60 \stackrel{\circ}{\circ}$ [equation (a) in Scheme 23]. ${ }^{[90]}$ The reaction was 4-5 times faster than when methanol or chloroform were used as solvents, and the DES was recovered after addition of water, filtration of the precipitated product and drying at $80^{\circ} \mathrm{C}$. In addition, the fluorophores 4,4-difluoro-4-bora-3a,4a-diaza-s-indacenes (BODIPYs) have also been dibrominated or diiodinated with NBS or NIS, respectively, using a DES based on the combination ChCl-1,1,1,3,3,3-hexafluoro-2-propanol (HFIP) at room temperature [equation (b) in Scheme 23]. ${ }^{[11]}$ After completion of the reaction, dichloromethane and water were added, and the dichloromethane layer yielded the product. The aqueous layer containing the DES was separated and dried, the medium could be reused several times with just a small decrease in the final yield.

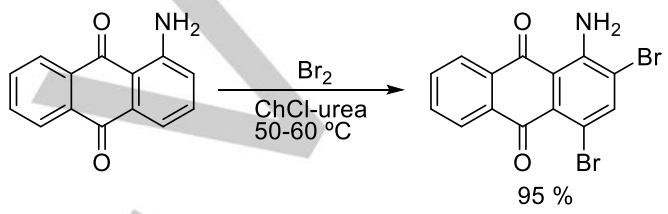

$$
\text { Re Alkyl, Aryl }
$$

Scheme 23. Halogenation of 1-aminoanthra-9,10-quinone and BODIPYs.

Reductions have also been explored using DES as medium. Thus, aldehydes with a variety of functional groups have been transformed into their corresponding alcohols with very high yields using sodium borohydride as reducing agent, and the combination $\mathrm{ChCl}$-urea as solvent at room temperature. ${ }^{[92]}$ In addition, cyclic and acyclic ketones, except aryl ketones, have also been reduced to the corresponding secondary alcohols under these reaction conditions with good yields. This procedure, although working at $60^{\circ} \mathrm{C}$, has shown to be suitable for the reductive opening of epoxides yielding secondary alcohols. Moreover, the same reducing agent/DES combination at room temperature has been used in the reductive amination of aromatic aldehydes and ketones with amines, driving to secondary amines (Scheme 24). ${ }^{[93]}$ Unfortunately, no attempts of reusing the DES were made in all these cases.

$$
\begin{aligned}
& \mathrm{R}^{1}=\mathrm{H}, \mathrm{Me} \\
& \mathrm{R}^{2}=\mathrm{H}, \mathrm{Cl}, \mathrm{NO}_{2}, \mathrm{COMe}, \mathrm{OH} \\
& \mathrm{R}^{3}=\mathrm{Ph}, \mathrm{nBu}
\end{aligned}
$$

Scheme 24. Reductive amination of aldehydes and ketones. 


\subsection{Alkylation Reactions}

Aromatic amines have been mono- $\mathrm{N}$-alkylated with alky bromides in DES (ChCl-urea) at $50^{\circ} \mathrm{C}$, avoiding the use of strong bases [equation (a) in Scheme 25)]. ${ }^{[94]}$ The formation of di-alkylated products resulted negligible and the DES was recovered by simple biphasic extraction with ethyl acetate. The process could be repeated for five successive cycles with only a slight yield decrease after the fourth cycle.

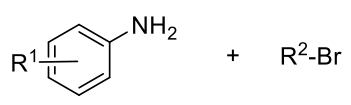

$\mathrm{R}^{1}=\mathrm{H}, \mathrm{Me}, \mathrm{F}, \mathrm{Cl}, \mathrm{NO}_{2}, \mathrm{OMe}$ $\mathrm{R}^{2}=n \mathrm{Hex}, n \mathrm{Bu}, \mathrm{Bn}$

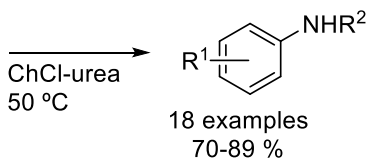

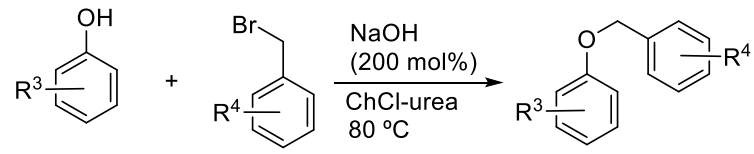

The DES was recovered after addition of water, filtration of the precipitated product, and evaporation of the water phase. The recovered DES was reused three times with minimal loss of activity. Similarly, indoles reacted with 1,3-dicarbonyl compounds using as solvent a mixture of $\mathrm{ChCl}$-oxalic acid at room temperature, affording C3-alkenylation products after a C3-alkylation/dehydration process. ${ }^{[97]}$

\subsection{Condensation Reactions}

Several condensation processes have been described in the last years employing DES as reaction media and promoter. Among them, the Knoevenagel condensation is probably one of the most studied, several works being employed for the synthesis of coumarin-derived compounds and other dyes. ${ }^{[98]}$ Thus, as an elegant example, $\mathrm{ChCl}$-urea was employed as DES in a three-step one-pot coumarin-styryl dye synthesis which involves two Knoevenagel reactions followed by an aldol-type condensation, the corresponding products being obtained in high global yields (Scheme 27). ${ }^{[99]}$
20 examples $75-96 \%$
$\mathrm{R}^{4}=\mathrm{H}, \mathrm{Me}, \mathrm{Cl}, \mathrm{F}_{3} \mathrm{C}, \mathrm{OMe}$
Scheme 25. Alkylation reactions of anilines and phenols.

The same DES was used in the O-benzylation of phenols bearing different functional groups, employing sodium hydroxide as base and working at $80{ }^{\circ} \mathrm{C}$ [equation (b) in Scheme 25)]. ${ }^{[95]}$ The DES was recovered by addition of water and extraction with ethyl acetate, followed by drying at $80{ }^{\circ} \mathrm{C}$, its reusability being tested for five consecutive cycles with a certain decrease in the yield after the fourth cycle.

The Lewis-acid free Friedel-Crafts alkylation of indoles with isatins has been achieved in DES. ${ }^{[96]}$ Thus, differently substituted indoles reacted with isatins in $\mathrm{ChCl}$-urea at room temperature to give the corresponding adduct in high yields (Scheme 26).

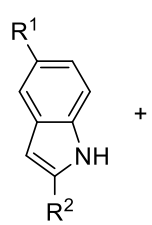

$\mathrm{R}^{1}=\mathrm{H}, \mathrm{Br}, \mathrm{OMe}$

$\mathrm{R}^{2}=\mathrm{H}, \mathrm{Me}$

$\mathrm{R}^{3}=\mathrm{H}, \mathrm{F}, \mathrm{Cl}, \mathrm{Br}, \mathrm{I}, \mathrm{NO}_{2}$

$\mathrm{R}^{4}=\mathrm{H}, \mathrm{Me}, \mathrm{Et}$

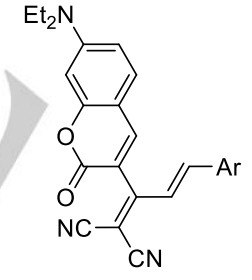

8 examples

$71-86 \%$ global yield
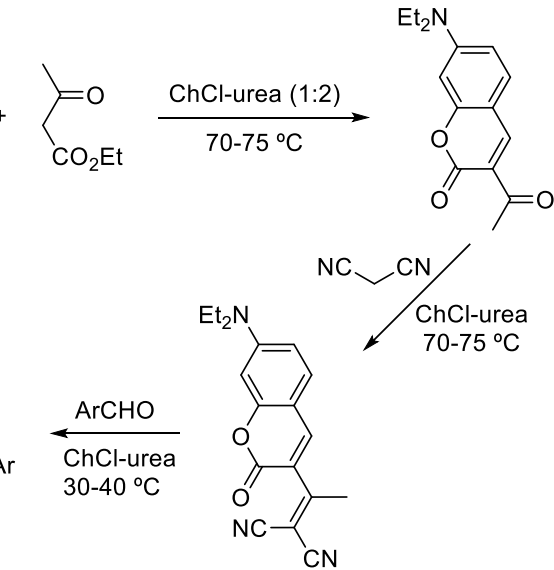

$\mathrm{CN}$
Scheme 27. Knoevenagel condensation for synthesis of coumarin-based dyes.

Different active methylene compounds have been successfully applied in this kind of transformation. Among them, two works in which the recyclability of the DES was tackled can be remarked. In the first one, a series of biologically active pyrimidinediones and pyrimidinetriones were synthesized by the condensation of different aldehydes and barbituric and thiobarbituric acids, rendering the corresponding products with high yields using $\mathrm{ChCl}$-urea at $40-45^{\circ} \mathrm{C}$ [equation (a) in Scheme 28]. The DES media was reused up to three times, after which the yield decreased considerably. ${ }^{[100]}$ In the second one, despite of being a simple Knoevenagel condensation between active methylene compounds and aromatic aldehydes, the use of DES mixture in catalytic amounts has proved very effective, the medium being recycled up to five times without any apparent loss in the yield [equation (b) in Scheme 28]. ${ }^{[101,102]}$ 


$$
\begin{aligned}
& \mathrm{ArCHO}+\underset{\mathrm{ChCl}}{\mathrm{Ch}} \\
& 9 \text { examples } \\
& \text { 91-98\% }
\end{aligned}
$$

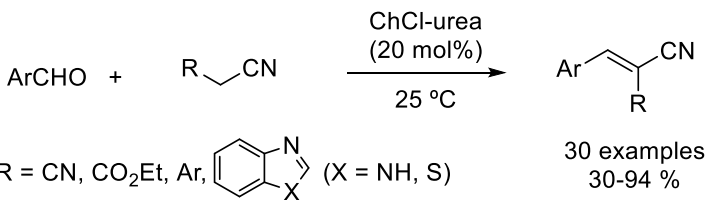

Scheme 28. Knoevenagel condensation

Another important condensation reaction carried out in DES mixtures are those involving the formation of imines. These compounds are easily synthesized in DES, as is shown in Scheme 29. Thus, at $60^{\circ} \mathrm{C}$, different aromatic aldehydes and ammonia or amines reacted smoothly affording the corresponding $N, N^{\prime}$-bis(arylmethylidene)arylmethane diamines and imines with good to excellent yields. ${ }^{[103]}$

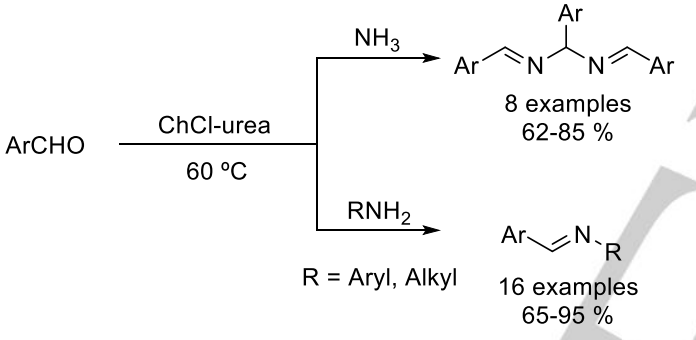

Scheme 29. Imines formation

The imine formation reaction is frequently involved in some nitrogen-containing heterocycle synthesis. Thus, $\mathrm{ChCl}$-urea has been used as DES for the acid-free Paal-Knorr synthesis of pyrrole derivatives. The reaction of different diones and amines took place at $80{ }^{\circ} \mathrm{C}$ affording the pyrroles with high yields. In the absence of the amine, the corresponding furans were also obtained (Scheme 30).

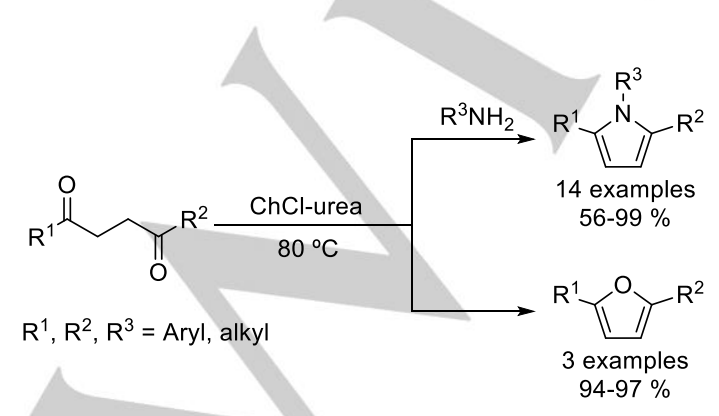

Scheme 30. Paal-Knorr reaction.
It is important to note that the use of other DES mixtures such as $\mathrm{ChCl}$-glycerol also gave rise to the desired products although in lower yields. In addition, the DES media was reused five-fold without detrimental in the yields. ${ }^{[104]}$

More recently, the synthesis of tetrahydrocarbolines through an acid-free Pictet-Spengler reaction has been reported (Scheme 31). Under the same aforementioned reaction conditions, tryptamine and different aldehydes (including aliphatics) were assayed obtaining the desired products in high yields. As in the previous case, the $\mathrm{ChCl}$-urea solvent was recycled up to four additional times with a negligible loss in the yield after a simple extraction of the tetrahydrocarbolines derivatives and evaporation of any residual organic solvent. ${ }^{[105]}$

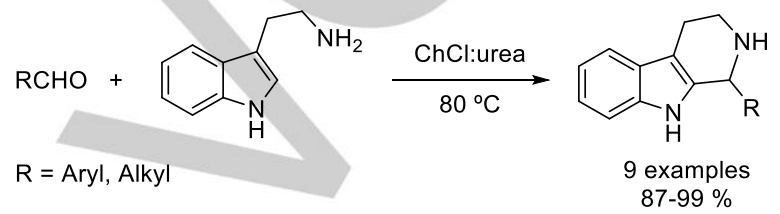

Scheme 31. Pictet-Spengler reaction.

Other $\mathrm{N}$-heterocyclic compounds have been synthesized using $\mathrm{ChCl}$-urea as solvent. Thus, oxazoles were easily prepared under mild reaction conditions, with the use of ultrasounds reducing the reaction time to minutes and increasing the yield in comparison to the thermal method [equation (a) in Scheme 32].

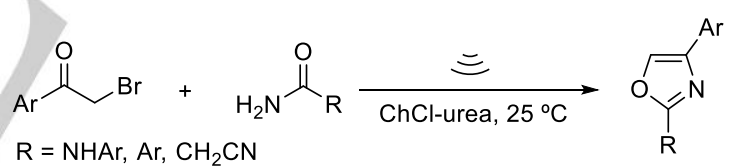

$$
\begin{aligned}
& 5 \text { examples } \\
& 82-90 \%
\end{aligned}
$$

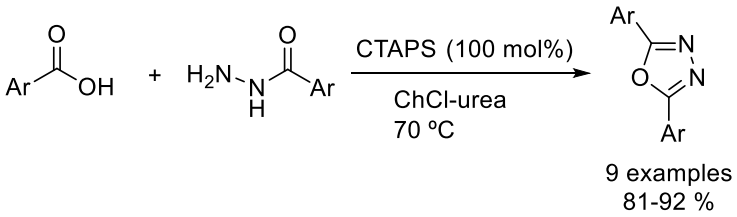

Scheme 32. Oxazole and oxadiazole syntheses.

The DES mixture was further reused four times without significant loss in yields. ${ }^{[106]}$ In another work, the same DES mixture was employed for the synthesis of oxadiazoles by condensation of acylhydrazides and benzoic acids. However, the use of cetyltrimethylammonium peroxodisulphate (CTAPS) as a reaction promoter was necessary for the cyclization to occur, otherwise only the corresponding diacylhydrazide was obtained. Apparently, this persulphate-based surfactant in the presence of water, which is generated in the diacylhydrazide 
formation step, generates cetrylammonium bisulphate in situ, which is acidic enough to promote the cyclization. The reaction was performed at $70{ }^{\circ} \mathrm{C}$ and yields obtained in all the cases were quite high [equation (b) in Scheme 32]. The recyclability of the reaction media was also studied and, although the yields still remained high, appreciable erosion of the results were observed after four consecutive reaction cycles. ${ }^{[107]}$.

$\mathrm{N}$-arylphthalimides were also straightforwardly synthesized in high yields by the condensation between phthalic anhydride and anilines in a $\mathrm{ChCl}$-urea mixture $\left(1: 2\right.$ molar ratio) at $80^{\circ} \mathrm{C}$. It is worth mentioning that the DES mixture $\mathrm{ChCl}$-malonic acid in an small amount ( $30 \mathrm{~mol} \%$ ) was also effective for this synthesis rendering similar yields, with methanol being used as solvent. In both cases, the recycling studies showed that the mixture can be reused for four additional times without detrimental in the yields (Scheme 33). ${ }^{[108]}$

$$
\text { + }
$$

Scheme 33. $\mathrm{N}$-arylphthalimide syntheses.

Other interesting condensation reactions have been reported to work efficiently in DES media. For example, the Perkin reaction between different aromatic aldehydes and acetic anhydride for the synthesis of cinnamic acids proceeded without any additive at $30{ }^{\circ} \mathrm{C}$ in high yields. It is important to remark that in a comparative study, the same reaction using a conventional method with sodium acetate as additive at $140^{\circ} \mathrm{C}$ and using as additive, afforded the same product in significantly lower yields (Scheme 34). The $\mathrm{ChCl}$-urea mixture was recycled for three times although with a slight decrease in yields. ${ }^{[109]}$

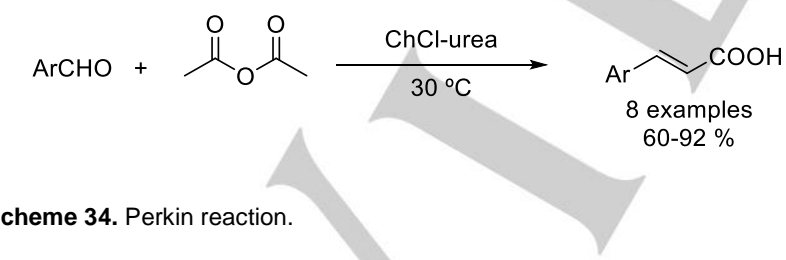

Finally, the coupling of aromatic aldehydes with indoles in ChCl-urea as DES, gave high yields of the corresponding bis(indolyl)methanes derivatives. The DES was reused four-fold with almost no loss in the final yield (Scheme 35$).{ }^{[110]}$

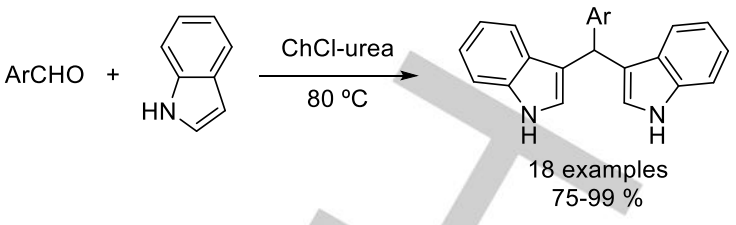

Scheme 35. Synthesis of bis(indolyl)methanes.

\subsection{Multicomponent Reactions}

Given the successful use of DES mixtures in condensation reactions shown in the previous section, it is not surprising that such reaction media were tested in several multicomponent reactions, since some of these processes involve a condensation in the reaction pathway.

In this sense, the synthesis of 1,4-dihydropyridines derivatives has been reported using the $\mathrm{ChCl}$-urea mixture [equation (a) in Scheme 36].

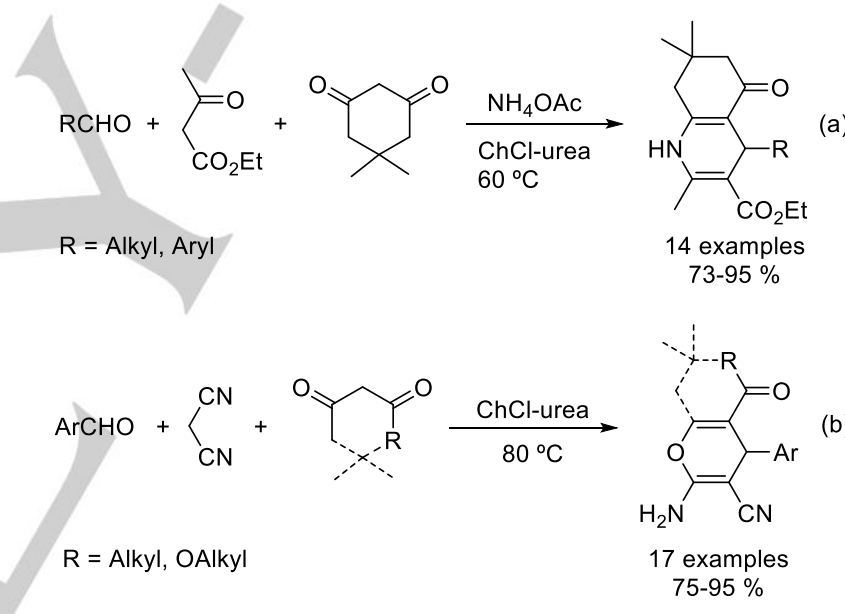

Scheme 36. Synthesis of 1,4-dihydropyridyl and pyranyl derivatives.

The products were obtained in few minutes with high yields at $60{ }^{\circ} \mathrm{C}$, and the DES was recycled five times with only a slight erosion in the yield. ${ }^{[111]}$ In this study, different DES mixtures were assayed, with the aforementioned one being the optimal.

Similarly, the synthesis of pyran and benzopyran derivatives has also been reported using the same reaction media, affording the corresponding products in high yields [equation (b) in Scheme 36]. ${ }^{[12]}$

A very close multicomponent process is the Ugi reaction. Thus, employing the previous DES mixture, a four-component Ugi reaction has been described, with the corresponding diamides being obtained in much higher yields than when using other commonly employed solvents. The DES mixture was submitted to recycling experiments and the yield remained constant for the three first cycles, dropping considerably afterwards (Scheme 37). ${ }^{[113]}$ 


$$
\mathrm{R}^{1} \mathrm{CHO}+\mathrm{R}^{2} \mathrm{NH}_{2}+\mathrm{PhCOOH}+{ }_{\mathrm{NC}}^{\stackrel{\mathrm{ChCl} \text {-urea }}{2{ }^{\circ} \mathrm{C}}}
$$

Scheme 37. Four-component Ugi reaction.

A multicomponent reaction has been used for the synthesis of quinazoline derivatives by condensation of isatoic anhydride and aromatic aldehydes and anilines. Among a wide variety of DES essayed, the use of the DES combination $\mathrm{ChCl}$ malonic acid as additive in $\mathrm{MeOH}$ as solvent gave rise to the corresponding products in high yields. The DES was used five times without apparent loss in yields (Scheme 38). ${ }^{[14]}$
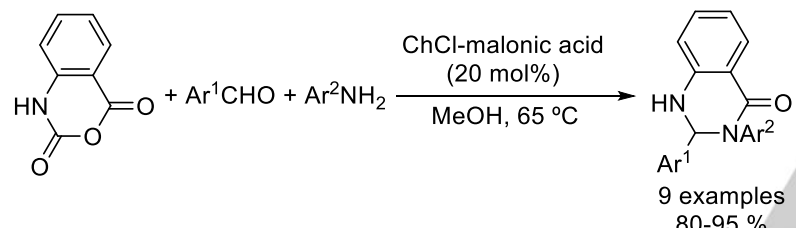

Scheme 38. Synthesis of quinazoline derivatives.

Other thoroughly multicomponent processes in DES media are those involving sulphur derivatives as reactants. Among them, it is worth to mention the high yielding synthesis of dithiocarbamates by the reaction of $\mathrm{CS}_{2}$ with a wide variety of amines and different nucleophiles such as epoxides, alkyl halides and Michael acceptors, with the latest one being also generated in situ by an aldol condensation (Scheme 39).

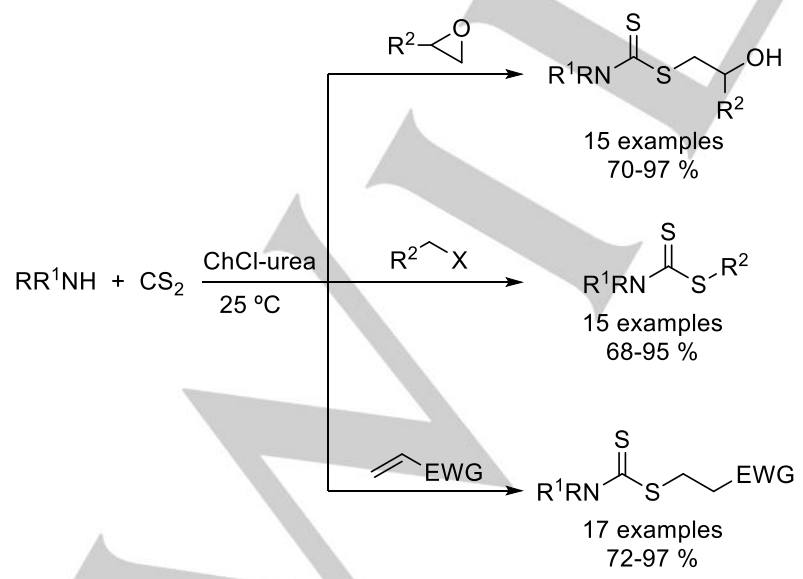

Scheme 39. Multicomponent dithiocarbamates synthesis.
The reaction proceeds smoothly at room temperature and in a short reaction periods, the DES being recyclable only for two additional runs, since a considerable drop in yield was observed afterwards. ${ }^{[115]}$

Finally, other interesting type of multicomponent transformations involving sulphur compounds carried out in a DES medium are those concerning the use of thiourea as odourless sulphur source. Thus, the reaction of thiourea with alkyl halides in the ChCl-urea mixture afforded the corresponding isothiouronium salt, which generated the corresponding thiolate along with urea (incorporated to the DES mixture) after basic hydrolysis. This thiolate reacted easily with different electrophiles, such as Michael acceptors and epoxides at $60{ }^{\circ} \mathrm{C}$, giving rise to the corresponding products in high yields [equation (a) in Scheme 40].

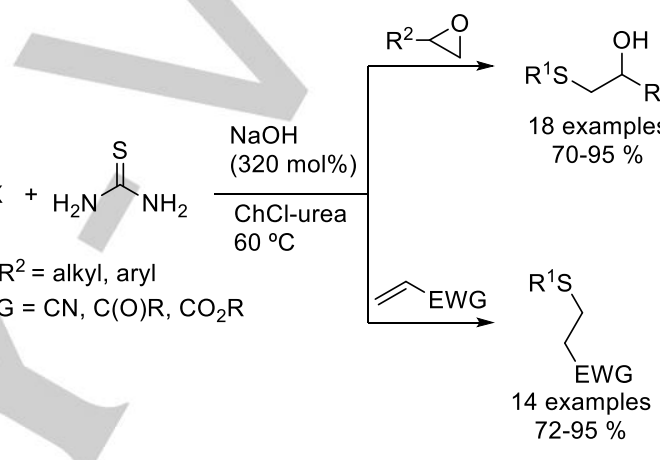

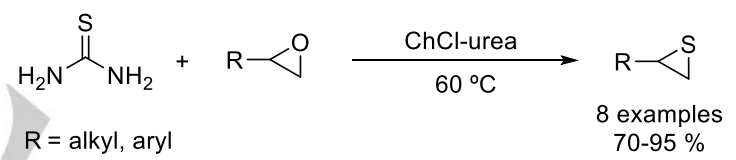

Scheme 40. Multicomponent reaction involving thiourea

In the case of the epoxides, and under the same reaction conditions but in the absence of alkyl halide and basic media, the process resulted in the formation of the corresponding thioepoxides in high yields [equation (b) in Scheme 40]. ${ }^{[116]}$

\subsection{Organometallic Reactions}

There are still few reported examples of organometallic reactions performed in DES. ${ }^{[17]}$ Thus, the addition of organolithium and Grignard reagents to ketones in choline chloride and glycerol has been reported (Scheme 41). The unusual achieved results were attributed to the formation of metallic ate complexes, ${ }^{[118]}$ although the microemulsion effect should not be misevaluate. The use of this DES as reaction medium allowed carrying out the processes in the presence of air with high selectivity at room temperature, without compromising the achieved yields. 


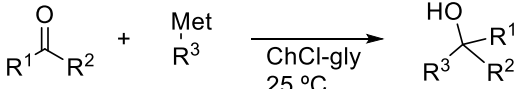

$$
\begin{aligned}
& \mathrm{R}^{1}=\text { Alkyl, Aryl } \quad 12 \text { examples } \\
& \mathrm{R}^{2}=\mathrm{Me}, \mathrm{Ph} \\
& \mathrm{R}^{3}=\text { Alkyl, Aryl, vinyl } \\
& \text { Met }=\mathrm{MgBr} \text {, } \mathrm{Li}
\end{aligned}
$$

Scheme 41. Grignard and organolithium reagents addition to ketones

The regioselective lithiation directed by a furan-ring followed by reaction with different electrophiles has also been performed in the aforementioned DES (Scheme 42). ${ }^{[119]}$

$$
\text { ii, }
$$

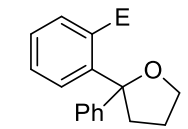

$\mathrm{E}^{+}=\mathrm{Ph}_{2} \mathrm{CO} ; 75 \%$ $\mathrm{E}^{+}=\mathrm{DMF} ; 90 \%$

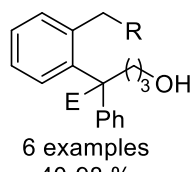
$40-98 \%$

Scheme 42. Organolithium deprotonations.

Thus, when one equivalent of strong base was used to perform the ortho-lithiation of the diaryltetrahydrofuran $(n=0)$ in cyclopentyl methyl ether (CPME) as solvent, the formed aryllithium species could be trapped with aromatic carbonyl compounds as electrophile in choline chloride-glycerol mixtures (ChCl-gly). However, when tolyl derivatives were used $(n=1)$ in a mixture of CPME-DES, the deprotonation at benzylic position was followed by elimination and ring-opening of tetrahydrofuran moiety. The addition of a second equivalent of lithium base to the in situ formed methylene unit generated a benzyllithium intermediate, which reacted with electrophiles such as alkyl halides or water, providing the corresponding modified 4,4diarylbutan-1-ol.

The ideal situation would be to perform metal-catalyzed reactions in DES. However, the number of reactions explored, until now, is very scarce and rare, with the scope of the reaction being unknown since only one or two examples have been carried out. In this area, for instance and following the periodic table order to introduce the results, it should be pointed out that scandium triflate has been used as Diels-Alder catalyst for the preparation of only one product using a combination of Lcarnitine-urea as DES (Scheme 43). Although, the media was chiral no enantiodifferentiation was found. ${ }^{[120]}$ The same reaction could be also carried out in carbohydrate melts as reaction medium or using L-proline ( $5 \mathrm{~mol} \%$ ) as catalyst with comparable yields and non-enantiodifferentiation.

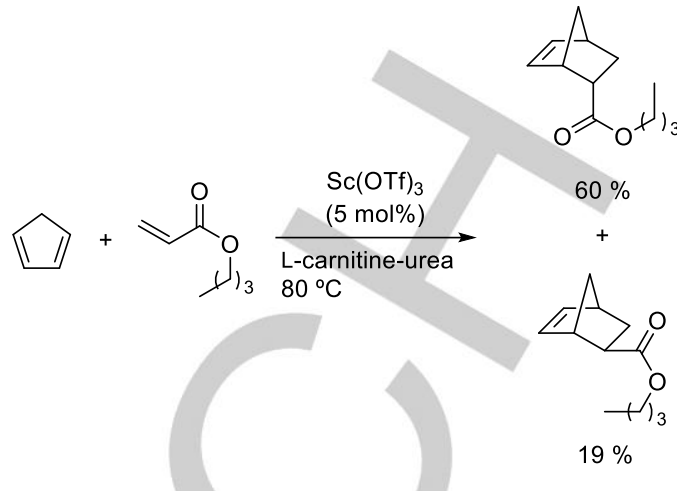

Scheme 43. Diels-Alder reaction.

Xylose and its polymeric structure, xylan, have been transformed into furfural by a simple dehydration process using different inorganic salts, including $\mathrm{FeCl}_{3}$ and $\mathrm{CrCl}_{3}{ }^{[121]}$ with moderate results (Scheme 44). The metal chloride accelerated the reaction rate of the furfural formation with both, metal-cation and chloride ion being partially responsible of this effect. The use of DES medium has a marginal effect in the reaction although it could be regard as a source of chloride and Brønsted acid. The reaction using aluminum chloride and choline chlorideoxalic acid has also been reported, providing similar results.

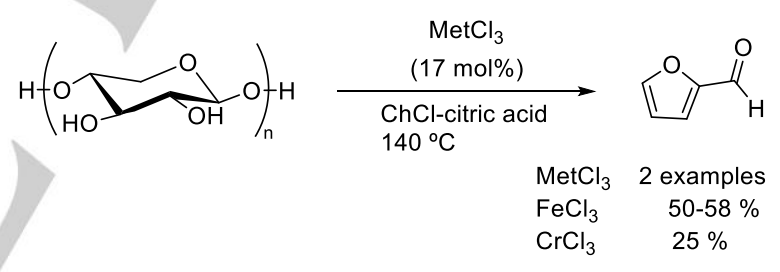

Scheme 44. Dehydration of xylose derivatives.

Oxidation reactions play a major role in industry, with the uses of innocent DES as reaction media to perform this type of processes being in its early stage of development. Very recently, the use of several DES, together with some metal salts or halides, has been tested to carry out the oxidation of toluene to benzaldehyde using hydrogen peroxide as oxygen source (Scheme 45).

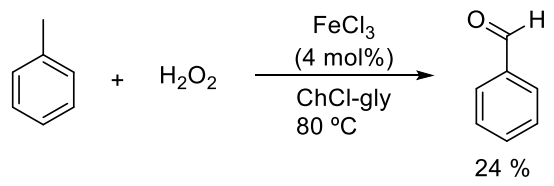

Scheme 45. Biphasic oxidation of toluene.

The best results were obtained when a biphasic nearly 1:1 volume mixture of toluene and choline chloride-ethylene glycol 
was used in the presence of $\mathrm{FeCl}_{3} \cdot{ }^{[122]}$ This reaction medium polarized effectively the hydrogen peroxide, promoting a Fentonlike oxidation reaction. The lower viscosity of chosen melt, compare to other DES, allowed a proper mass-transfer process improving the results.

The [3+2]-dipolar cycloaddition of benzyl azide and phenylacetylene has been described using two different ureabased DES, without any significant difference between them (Scheme 46). It should be pointed out that the same product could be obtained with similar yield through a three-component approach. ${ }^{[120]}$ In both cases, no additional base was necessary due to the reversible proton accepting properties of the melt. The process was performed in one-pot protocol starting from the corresponding benzyl bromide and potassium azide instead of organic azide, with similar results being achieved in the sorbitol based DES, and lower yield being obtained (55\%) in the carnitine-urea mixture.

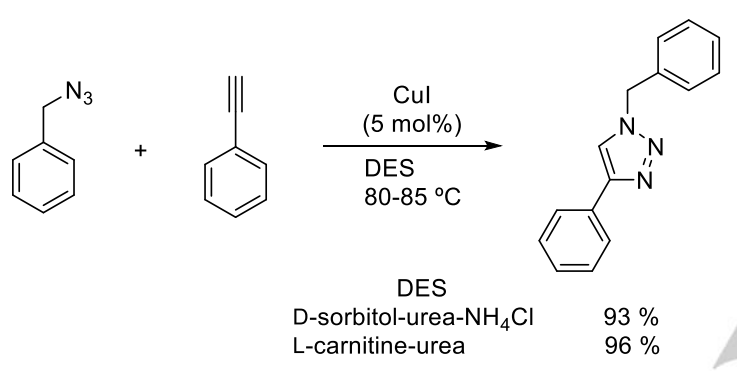

Scheme 46. [3+2]-Dipolar cycloaddition.

Nanoparticles of delafossite $\left(\mathrm{CuFeO}_{2}\right)$ have been used as recyclable catalyst for the synthesis a wide range of imidazo[1,2a]pyridines through the multicomponent coupling of different 2aminopyridines, aldehydes and arylacetylenes using a mixture of citric acid and dimethyl urea (DMU) as medium (Scheme 47). The reaction did not proceed at all in the absence of solvent or in other common polar organic solvent, showing that DES played an important role not only as reaction media but also providing the adequate environment for the real catalytic species The catalyst was easily isolated by magnetic decantation and the reagents, products and by-products were obtained at the end of the process by extraction with ethyl acetate, recovering the DES. Following this methodology, both catalyst and DES could be reused six times without any detrimental effect on the yield. ${ }^{[123]}$
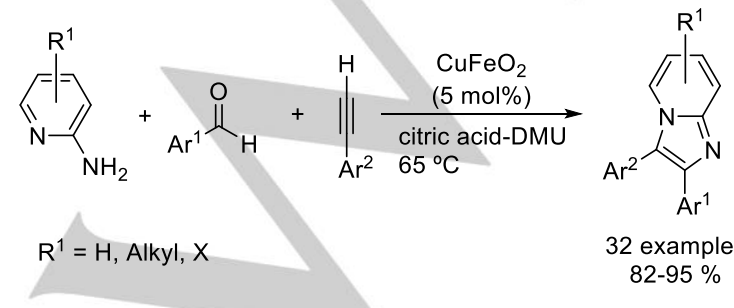

32 examples $82-95 \%$
Tetraisoquinoline derivatives are compounds of great interest since they display biological and pharmaceutical properties. Their synthesis could be efficiently accomplished by a cross-dehydrogenative coupling reaction using copper oxide impregnated in magnetite using choline chloride-ethylene glycol as medium and air as oxidant, in this way the only waste of the process was water (Scheme 48). Curiously, a direct relationship between the conductivity of DES used and the yield obtained was observed. ${ }^{[124]}$ In this process, several $\mathrm{N}$-protected tetrahydroisoquinolines reacted with different nucleophiles, such as 1-alkynes, silylenol ethers, methyl ketones, alkenyl boronates, indole derivatives, affording the corresponding a-substituted tetrahydroisoquinolines with excellent yields. The use of DES was essential since when the same protocol was tested in volatile organic media the achieved product was not the desired one. The DES medium and the catalyst was recovered by simple extraction of the product (and unreactive reagents) using cyclopentyl methyl ether and reused at least for ten times without any detrimental effect on the final result.
$\operatorname{Ar}$

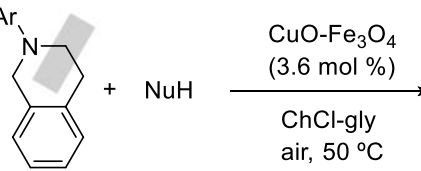

$\mathrm{NuH}=\mathrm{R} \equiv$, Ketones, $\mathrm{MeNO}_{2}$ $\mathrm{HOP}(\mathrm{OEt})_{2}$, Indole, $\mathrm{R}^{\prime} \mathrm{BF}_{3} \mathrm{~K}$

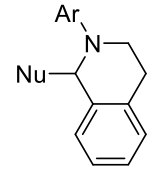

20 examples $37-95 \%$
Scheme 48. Cross-dehydrogenative coupling reaction.

The aforementioned examples used only simple inorganic salt as transition metal catalysts. However, examples where the catalytic activity of complexes could be fine-tuned due to the organic ligand backbone are far more interesting. Thus, isomerization of allylic alcohols to ketones has been performed in choline chloride and glycerol (gly) as solvent (Scheme 49) using different ruthenium complexes. ${ }^{[125]}$

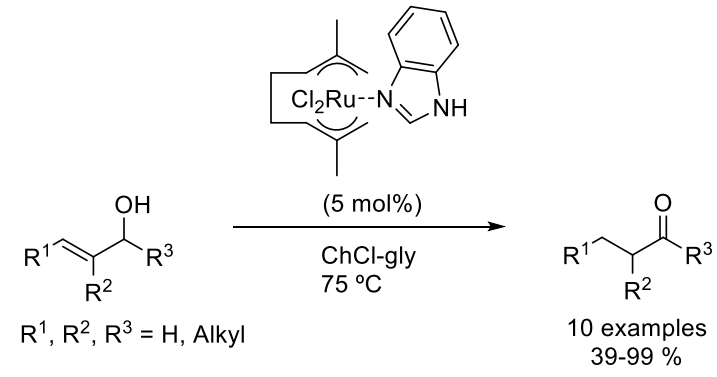

Scheme 49. Allylic alcohol isomerization.

This is an excellent example to show the fine tuning of the ligand with the exceptional solvent properties. When the reaction was catalyzed by similar ruthenium species, in the absence of the benzimidazole unit or replacing it by 1-methylimidazole, 
these new complexes were unable to enter into the typical hydrogen bond DES network as the donor, and therefore the results were significantly inferior in terms of yields and reaction times, thus highlighting the important role of ligand in its interaction with solvent. The chosen ruthenium ligand and solvent could be reused four times in this process showing similar activities.

There are only two examples of rhodium catalyzed reactions using DES (Scheme 50). Thus, the Wilkinson catalyst has been used in the hydrogenation (1 atm) of a typical dehydroamino acid in citric acid-dimethyl urea (DMU), giving the expected phenylalanine derivative in quantitative yield. ${ }^{[126]}$

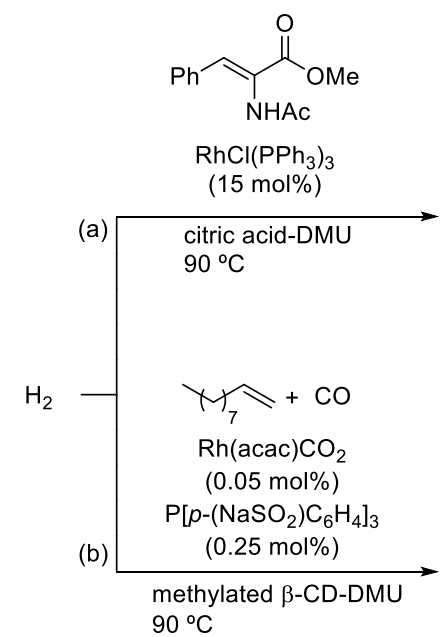

Scheme 50. Rhodium catalyzed reactions.<smiles>COC(=O)C(Cc1ccccc1)NC(C)=O</smiles>

$99 \%$

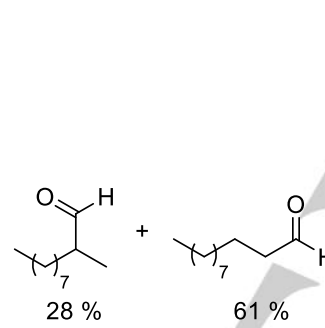

$28 \%$ $61 \%$

More interesting was the hydroformylation of 1-decene using methylated $\beta$-cyclodextrine (methylated $\beta-C D$ ) and dimethyl urea. ${ }^{[127]}$ The conversion depended on the cavity size of cyclodextrine component, with the viscosity of the medium being inversely proportional correlated with the conversion of the reaction and the solubility of alkene being proportional correlated with the obtained yield. The use of an anionic phosphine ligand resulted of capital importance in order to keep the transition metal catalyst in the DES phase and not in the alkene one.

The important and extended palladium chemistry has been initially tested in DES media. The first application was the classical Suzuki reaction, using a ternary mixture of mannitol, dimethyl urea and ammonium chloride as DES combination. The yield was excellent after $6 \mathrm{~h}$ reaction time [equation (a) in Scheme 51]. ${ }^{[126]}$

The results obtained in the Stille reaction were more interesting ${ }^{[128]}$ since triphenylarsine was the best ligand for the palladium catalyst formation [equation (b) in Scheme 51]. Under these conditions, and after $2 \mathrm{~d}$ reaction time, the obtained yield for the coupling of 4-bromoanisole and tetraphenylstannane was $87 \%$. When the same reaction was repeated using no ligand the yield dropped to $27 \%$. However, when the reaction was carried out using [1,1'-biphenyl]-2-yldicyclohexylphosphane (Hartwig-
Buchwald ligand), an excellent phosphine for palladium chemistry, only a modest $61 \%$ yield was obtained. These facts clearly demonstrate the importance of a rational design of the ligand in order to get good results in such an unusual medium as DES's. Under these reaction conditions, the repeated use of the catalyst-melt mixture was possible, with the product isolation not requiring the use of organic solvents.

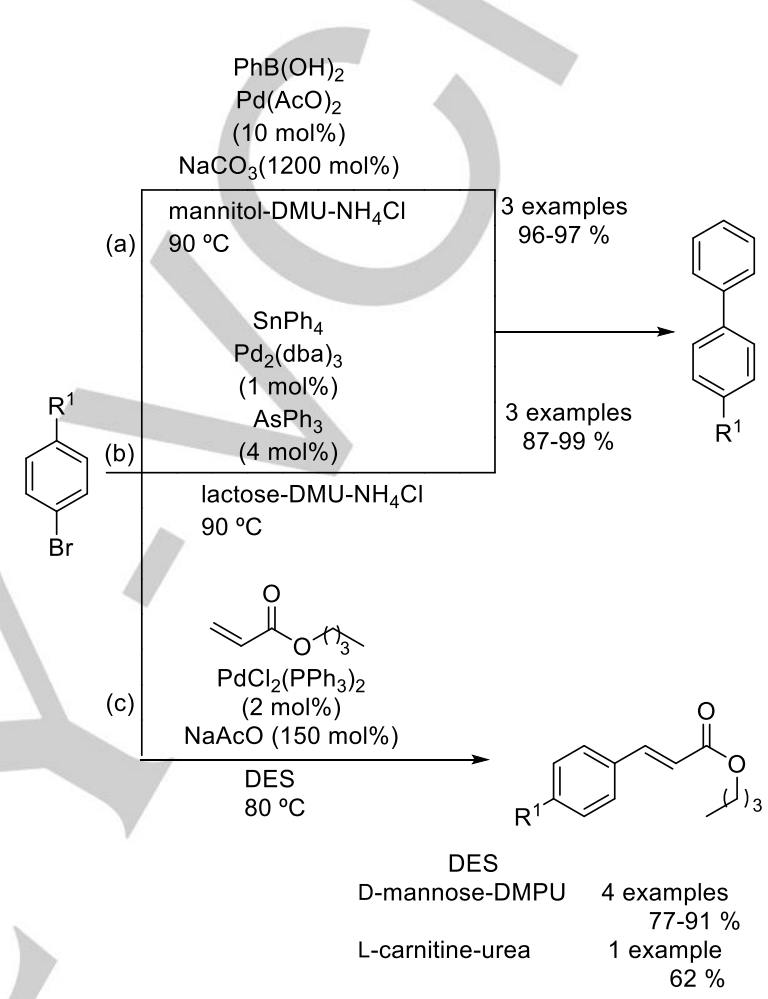

Scheme 51. Palladium catalyzed cross-coupling reactions.

The Heck cross-coupling reaction has also been tested in two different DES mixtures, showing that D-mannose-dimethyl urea was a slightly better medium than the L-carnitine-urea [equation (c) in Scheme 51]. ${ }^{[120]}$ The aforementioned Dmannose-DMU melt was also the solvent of choice to perform the copper-free Sonogashira coupling reaction of aryl bromides with phenylacetylene in the presence of an excess of diisopropylamine and $\mathrm{PdCl}_{2}\left(\mathrm{PPh}_{3}\right)_{2}$ (2 $\left.\mathrm{mol} \%\right)$, as catalyst, obtaining the expected product in $61 \%$ yield starting from phenyl bromide and $79 \%$ yield from 4-nitrophenyl bromide.

In addition, the Tsuji-Trost allylation of amines has been carried out using methylated $\beta$-cyclodextrine and dimethyl urea. $^{[127 a]}$ The DES-catalyst became solid at room temperature, allowing the easy isolation of the organic layer and recycling and reusing the whole media for eight times, without loss of the initial activity (Scheme 52). The catalyst species maintained in the solid state after the reaction was thus protected against degradation, allowing the change of substrates from one reaction cycle to another. 


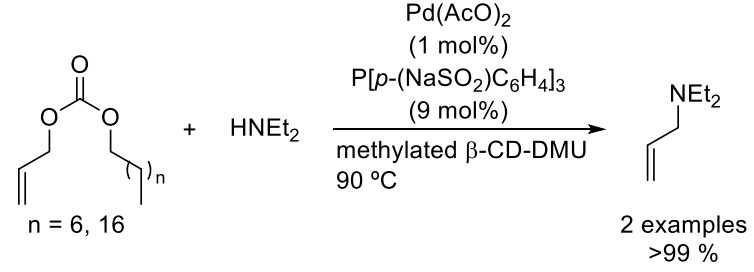

Scheme 52. Tsuji-Trost allylation.

Finally, it is worth mentioning that a gold chloride complex has shown to be an excellent catalyst for the cycloisomerization of $\mathrm{Y}$-alkynoic acids into enol-lactones in DES [Scheme 53; equation (a)]. The best results were achieved using choline chloride-urea as solvent, probably due to the basic character of the mixture. The catalytic system could be recycled up to four times without depletion on the yield but doubling the reaction times, under aerobic conditions. ${ }^{[129]}$
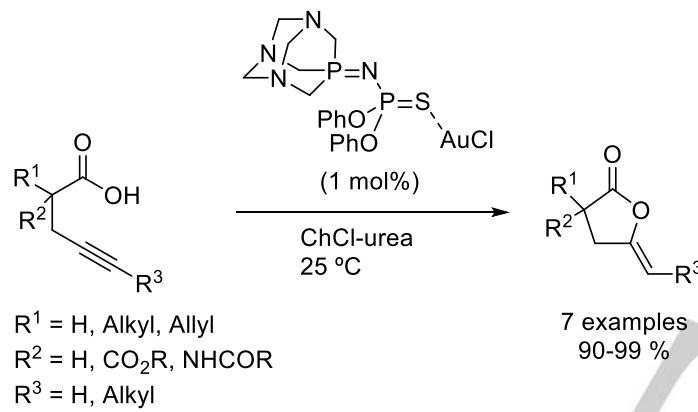

(a)

$$
\begin{gathered}
7 \text { examples } \\
90-99 \%
\end{gathered}
$$

$\mathrm{R}^{3}=\mathrm{H}$, Alkyl

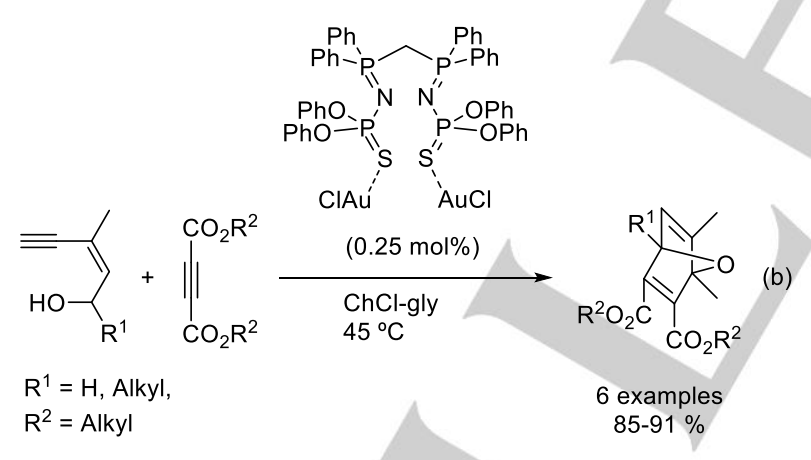

Scheme 53. Gold catalyzed reactions.

A similar bimetallic gold chloride complex has been used in the one-pot tandem cycloisomerization of $(Z)$-enynols to substitute furans and in the Diels-Alder reaction with acetylenedicarboxylates [Scheme 53; equation (b)]. ${ }^{[130]}$ The presence of bis-imino phospane ligand is crucial for the selectivity and efficiency of the cycloisomerization process, since the use of simple $\mathrm{AuCl}\left(\mathrm{SMe}_{2}\right)_{2}$ as catalyst rendered lower results. The use of DES, in both transformations, avoided the employment of a co-catalyst, such as a silver salt, for the chloride abstraction. Probably, the tridimensional proton structure of solvent made very easy the formation of cationic gold by breaking of Au-Cl bond.

\subsection{Biocatalyzed Processes}

Particularly interesting has been the development in the last years of biotransformations carried out in DES, ${ }^{[3]}$ something not too obvious as strong hydrogen-bond donors like urea denature proteins. In addition, DES also contain halides, which inactivate or inhibit proteins. In spite of these possible problems, it has been found that many enzymes retain its activity in DES. Thus, the first reported example on this topic employed hydrolases as biocatalysts, as in the lipase-catalyzed transesterification of ethyl valerate with 1-butanol or its aminolysis reaction with 1-butylamine, which showed good catalytic activity in DES such as $\mathrm{ChCl}$-urea or $\mathrm{ChCl}$-gly. ${ }^{[131]}$ Other example of an interesting enzymatic process of significant industrial importance promoted by a hydrolase, employed $\alpha$ chymotrypsin for a peptide synthesis in DES. ${ }^{[132]}$ In this case, the synthesis of the protected $\mathrm{N}$-Ac-Phe-Gly- $\mathrm{NH}_{2}$ peptide in different DES (ChCl-gly, ChCl-urea, $\mathrm{ChCl}$-isosorbide, $\mathrm{ChCl}$-xylitol) was achieved, starting from $\mathrm{N}$-acetylphenylalanine ethyl ester and glycinamide hydrochloride (Scheme 54). This enzymatic DESprocedure avoided a detrimental hydrolysis pathway observed in aqueous media. The suspended enzyme could be reused several times by simple filtration with excellent to moderate activities.

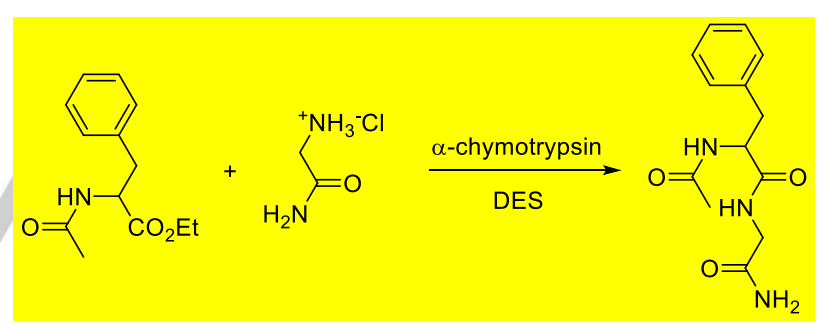

Scheme 54. Enzyme-promoted peptide coupling reaction in DES

Benzaldehyde lyase (BAL), has been found suitable to catalyze the enantioselective $\mathrm{C}$-C-forming carboligation of aldehydes in different DES-phosphate buffer mixtures (Scheme 55). ${ }^{[133]}$ Thus, by using $\mathrm{ChCl}$-gly as DES, BAL remained fully active with excellent enantioselectivity $(>99 \%$ ee in the case of benzaldehyde) at 60:40 DES-buffer (v/v), whereby a significant denaturation is observed at 70:30 mixtures.

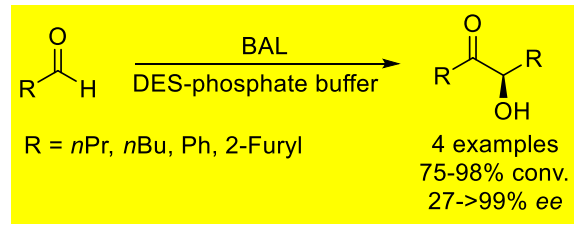

Scheme 55. BAL-promoted enantioselective carboligation of aldehydes. 
Whole-cell biocatalysis can also be performed in DES. Thus, baker's yeast has been employed in mixtures of water with DES ( $\mathrm{ChCl}$-gly), achieving the enantioselective reduction of the ketone group in ethyl acetylacetate to the corresponding alcohol in ethyl 3-hydroxybutanoate. ${ }^{[134]}$ This reduction is observed for long reaction times $(>200 \mathrm{~h})$, suggesting that the cells remain stable in DES. Interestingly, a complete inversion of the enantioselectivity is observed by changing the proportion of the DES added, from approximately $95 \%$ ee $(S)$ in pure water to approximately $95 \%$ ee $(R)$ in the pure DES. Presumably, some (S)-oxidoreductases present in baker's yeast are inhibited by the presence of DES. In addition, recombinant whole cells overexpressing oxidoreductases have been employed as biocatalysts for the stereoselective reduction of alkyl phenyl ketones in different DES (ChCl-gly)-aqueous-media solutions, the enantiomeric excesses obtained being increased significantly if DES is present. ${ }^{[135]}$

\subsection{Miscellaneous}

Carbon-carbon bond formation reactions are the most important transformations for the synthesis of complex molecules. In the case of the aldol reaction, the process is generally catalyzed by using inorganic or organic bases, with an organocatalyzed approach being introduced more recently. Although DES has been used with organometallic complexes and biocatalysts, the use of organocatalysts under these conditions remained unexplored until very recently. ${ }^{[136]}$ Thus, the use of DES has allowed to combine the biocatalyzed transformation of vinyl acetate into acetaldehyde, using an immobilized lipase as biocatalyst, with the cross aldol reaction of the in situ formed aldehyde with other aromatic aldehydes catalyzed by a prolinol derived organocatalyst (Scheme 56).

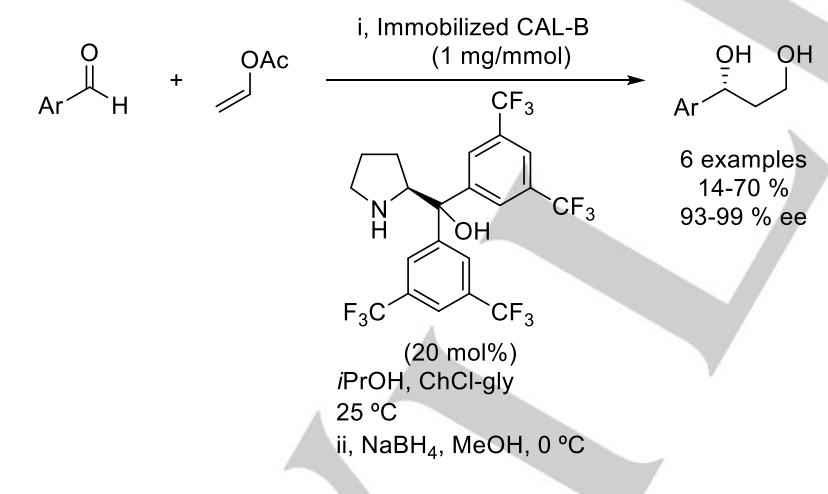

Scheme 56. Tandem transesterification-aldol process.

The corresponding aldol products were further transformed into 1,3-diols by reduction with good overall yields and enantioselectivities. Remarkably, this is the first reported enantioselective organic non-enzymatic reaction performed in DES. ${ }^{[136 a]}$ The DES and CAL-B were reused at least for six times without loss of the initial activity. However, the addition of fresh organocatalyst was required in each cycle in order to maintain the reaction conversion, since the final work up of the reaction with VOC solvents partially extracted this catalyst from the DES medium.

The Henry reaction of arenecarbaldehydes with nitromethane has been accomplished in the classical choline chloride-urea mixture and using methanol as co-solvent yielding the expected $\beta$-hydroxy nitroalkane derivatives ( 9 examples, 69 $95 \%$ yield). ${ }^{[137]}$

Other important $\mathrm{C}-\mathrm{C}$ bond-forming reaction is the Michaeltype addition of suitable nucleophiles, such as nitrometane, ethyl cyanoacetate, and malonitrile to $\alpha, \beta$-unsaturated ketones (Scheme 57). This transformation has been performed by using the synergetic effect of ultrasound irradiation and a minimum amount of choline-urea (5 mol\%). ${ }^{[138]}$ The DES medium could be recovered and reused at least four times without depletion of the initially obtained yields, after ethyl acetate extraction of products.

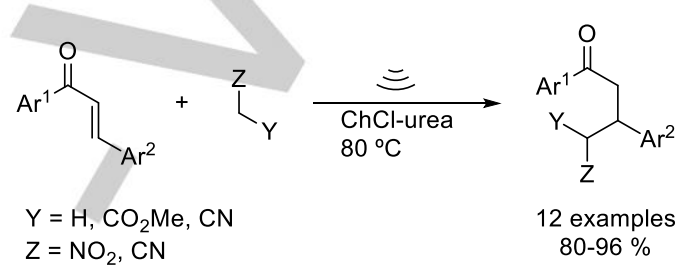

Scheme 57. Michael Reaction

The same DES combination (choline chloride-urea) has been used to carry out a tandem Michael-elimination process, providing the synthesis of aromatic tricianovinyl derivatives (Scheme 58). The results were comparable to those obtained by using biocatalysts in organic solvents. The DES was recovered by adding water to the reaction mixture since final products were insoluble. After filtration, and water evaporation under vacuum, the DES was used four times without any loss of activity. ${ }^{[139]}$ Instead of anilines, 2-methyl- $1 \mathrm{H}$-indoles (3 examples) could be used as nucleophilic partners, obtaining the corresponding 3vinylindoles with similar results to those obtained in the case of anilines.

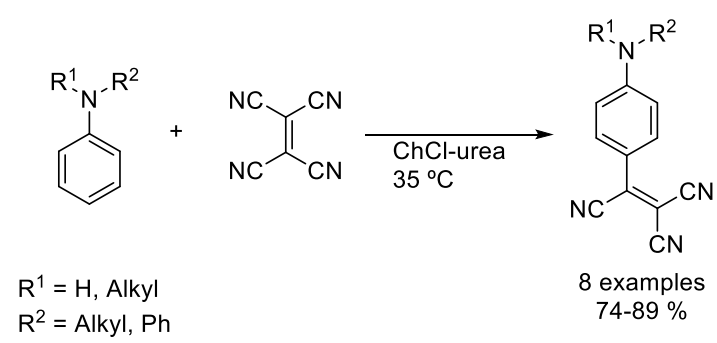

Scheme 58. Tandem Michael-elimination process.

The beneficial effect of urea as one of the component of the DES mixture was also demonstrated in the multistep synthesis of isoxazoles (Scheme 59) and related 
isoxazolines. ${ }^{[140]}$ The nucleophilic mixture allowed the initial condensation, followed by chlorination to give the corresponding imidoyl chloride. Surprisingly, the DES did not react with the high electrophilic intermediates. In fact, it seems that urea favors the release of chloride from the imidoyl intermediate, giving the 1,3dipolar component which smoothly reacted with alkynes to give the corresponding isoxazoles. When alkenes were used in this last cycloaddition step, the corresponding isoxazolines were isolated with good yields (9 examples, 42-91\%). A similar dipolar cycloaddition was explored performing the reaction with ethyl nitroacetate, as starting source of 1,3-dipolar component. In this case, the best reaction mixture was acetyl choline chloride and urea, leading to different isoxazoles in good results (5 examples, 63-91\%), after reaction with the corresponding alkynes. The recyclability of the DES was proved since after decantation of products with toluene the DES mixture could be reused at least for five times without any decrease on the reaction yields.

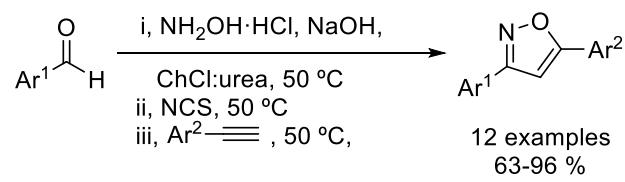

Scheme 59. One-pot three-step synthesis of isoxazoles.

\section{Conclusion}

Deep eutectic solvents can replace satisfactory any common petrol-derived VOC solvents, in organic reactions, as it has been proved along this microreview. The physical properties of these mixtures, such as density, polarity, etc., could be fined adjusted by the correct election of partners, including the formation of ternary mixtures. Moreover, these mixtures have very low inflammability, volatility and price, and high availability. Many DES components come from natural sources, which ensure low toxicity and high biodegradability, and renewability. All these facts highlight the broad possibilities of DES as substitutes of hazardous organic solvents, making the organic synthesis more sustainable as well as reducing its negative impact on the environment. There are many industrial advantages recommending the use of DES. Nevertheless, the lack of explored methodologies, such as the few reported examples using organometallic chemistry or the practically inexistent enantioselective versions of the aforementioned reactions, are slowing the possible jump of DES to the industry. In the near future, the academia will provide new synthetic procedures, organometallic complexes, chiral ligands and so on, capable to increase the possible transformations using deep eutectic solvents No doubt that, sooner than later, exciting applications of the DES will boost their incorporation to industrially-useful processes.

\section{Acknowledgements}

This work was supported by the University of Alicante (VIGROB173 and UAUSTI13-09).

Keywords: Green Chemistry • Environmental Chemistry • Renewable Resources • Sustainable Chemistry • Waste Prevention

[1] http://www.un.org/millennium/declaration/ares552e.pdf.

[2] D. J. C. Constable, C. Jiménez-González, R. K. Henderson Org. Process Res. Dev. 2007, 11, 133-137.

[3] a) T. Laird, Org. Process Res. Dev. 2012, 16, 1-2; b) G. M. Kemeling ChemSusChem 2012, 5, 2291-2292.

[4] R. K. Henderson, C. Jiménez-González, D. J. C. Constable, S. R Alston, G. G. A. Inglis, G. Fisher, J. Sherwood, S. P. Binks, A. D. Curzons, Green Chem. 2011,13, 854-862.

[5] A. Amelio, G. Genduso, S. Vreysen, P. Luis, B. Van der Bruggen Green Chem. 2014, 16, 3045-3063.

[6] R. A. Sheldon, Chem Soc. Rev. 2012, 41, 1437-1451.

[7] K. Tanaka Solvent-Free Organic Synthesis, Wiley-VC, Wenheim, 2003.

[8] a) U. M. Lindström, Chem. Rev. 2002, 102, 2751-2772; b) C.-J. Li Chem. Rev. 2005, 105, 3095-3165; c) Aqueous-Phase Organometallic Catalysis, $2^{\text {nd }}$ edition (Eds.: B. Cornils, W. A. Herrmann), Wiley-VC, Wenheim, 2004; d) Metal-Catalyzed Reactions in Water; (Eds.: P. H. Dixneuf, V. Cadierno), Wiley-VC, Wenheim, 2013.

[9] I. A. Shuklov, N. V. Dubrovina, A. Börner, Synthesis 2007, 2925-2943.

[10] a) T. Matsuda, Asymmetric Catalytic Synthesis in Supercritical Fluids in Catalytic Methods in Asymmetric Synthesis: Advanced Materials, Techniques, and Applications, (Eds.: M. Gruttadauria, F. Giacalone) John Wiley \& Sons, Hoboken, 2011, pp. 373-390; b) R. Mahboub, C. R. Chimie, 2011, 14, 476-482; c) H. Machida, M. Takesue, R. L. Smith, J. Supercrit. Fluids, 2011, 60, 2-15; d) E. J. Beckman, J. Supercrit. Fluids, 2012, 68, 949-958; e) J. Zhang, B. Han, Acc. Chem. Res. 2013, 46 425-433; f) H. Zhang, S. Heinonen, E. Levänen, RSC Adv. 2014, 4 61137-61152.

[11] N. S. Kus, Tetrahedron, 2012, 68, 949-958

[12] S. Aparicio, R. Alcalde, Green Chem. 2009, 11, 65-78.

[13] a) Y. Gu, F. Jérôme, Green Chem. 2010, 12, 1127-1138; b) A. E. DíazÁlvarez, J. Francos, P. Croche, V. Cadierno, Curr. Green Chem. 2014, 1, 51-65; c) F. Chahdoura, I. Favie, M. Gómez, Chem. Eur. J. 2014, 20 , 10884-10893.

[14] a) V. Pace, P. Hoyos, L. Castoldi, P. Domínguez de María, A. R Alcántara, ChemSusChem 2012, 5, 1369-1379. b) M. Pérez-Sánchez, M. Sandoval, M. J. Hernáiz, P. Domínguez de María, Curr. Org. Chem. 2013, 17, 1188-1199.

[15] a) M. J. Earle, K. R. Seddon, Pure Appl. Chem. 2000, 72, 1391-1398; b) P. Wasserscheid, W. Keim, Angew. Chem. 2000, 112, 3926-3945; Angew. Chem. Int. Ed. 2000, 39, 3772-3789; c) J. Dupont, J. D. Scholten, Chem. Soc. Rev. 2010, 39, 1780-1804; d) J. P.Hallet, T. Welton, Chem. Rev. 2011, 111, 3508-3576. e) M. A. P. Martins, C. P. Frizzo, A. Z. Tier, D. N. Moreira, N. Zanatta, H. G. Bonacorso, Chem. Rev. 2014, 114, PR1-PR70; f) T. Itoh, Organic synthesis using an ionic liquid as reaction media, in Environmentally Friendly Synthesis Using Ionic Liquids,(Eds.: J. Dupont, T. Itoh, P. Lozano, S. V. Mahotra), CRC Press, Boca Raton, 2014, pp. 9-30. g) J. D. Scholten, B. A. D. Neto, P. A. Z. Suarez, J. Dupont Organic synthesis using an ionic liquid as reaction media, in Environmentally Friendly Synthesis Using Ionic Liquids, (Eds.: J. Dupont, T. Itoh, P. Lozano, S. V. Mahotra), CRC Press, Boca Raton, 2014, pp. 109-138; h) H.-P. Steinrück, P. Wasserscheid, Catal. Lett. 2015, 145, 380-397; i) E. García-Verdugo, B. Altava, M. I. Burguete, P. Lozano, S. V. Luis, Green Chem.2015, 17, 2693-2713. 
[16] T. Welton, Green Chem. 2011, 13, 225

[17] See for instance: a) R. P. Rastogi, P. S. Bassi, J. Phys. Chem. 1964 68, 2398-2406; b) M. Gambino, P. Gaune, M. Nabavian, M. GauneEscard, J. P. Bros, Thermochim. Acta 1987, 111, 37-47; c) I. Gill, E. Vulfson, Trends Biotechnol. 1994, 12, 118-122; d) R. J. Davey, J. Garside, A. M. Hilton, D. McEwan, J. W. Morrison, Nature 1995, 375 664-666.

[18] R. E. Pincock, Acc. Chem. Res. 1969, 2, 97-103

[19] a) A. P. Abbott, G. Capper, D. L. Davies, H. L. Munro, R. K. Rasheed, V. Tambyrajah, Chem. Commun. 2001, 2010-2011; b) A. P. Abbott, G. Capper, D. L. Davies, R. K. Rasheed, V. Tambyrajah, Chem Commun. 2003, 70-71; c) A. P. Abbott, D. Boothby, G. Capper, D. L. Davies, R. K. Rasheed, J. Am. Chem. Soc. 2004, 126, 9142-9147.

[20] E. L. Smith, A. P. Abbott, K. S. Ryder, Chem. Rev. 2014, 114, 11060 11082.

[21] C. Ruß, B. König, Green Chem. 2012, 14, 2969-2982.

[22] M. Francisco, A. van den Bruinhorts, M. C. Kroon, Angew. Chem. 2013, 125, 3152-3163; Angew. Chem. Int. Ed. 2013, 52, 3074-3085.

[23] a) A. P. Abbott, K. El Ttaib, G. Frisch, K. J. McKenzie, K. S. Ryder, Phys. Chem. Chem. Phys. 2009, 11, 4269-4277; b) A. P. Abbott, R. C. Harris, K. S. Ryder, C. D’Agostino, L. F. Gladden, M. D. Mantle, Green Chem. 2011, 13, 82-90.

[24] Y. Dai, J. van Spronsen, G-J. Witkamp, R. Verpoorte, Y. H. Choi, Anal. Chim. Acta 2013, 766, 61-68.

[25] M. Hayyan, M. A. Hashim, A. Hayyan, M. A. Al-Saadi, I. M. AINashef, M. E. S. Mirghani, O. K. Saheed, Chemosphere 2013, 90, 2193-2195.

[26] a) K. Radošević, M. C. Bubalo, V. G. Srček, D. Grgas, T. L. Dragičević, I. R. Redovniković, Ecotox. Environ. Safe, 2015, 112, 46-53; b) B.-Y Zhao, P. Xu, F.-X. Yang, H. Wu, M.-H. Zong, W.-Y. Lou, ACS sustainable Chem. Eng. 2015, 3, 2746-2755.

[27] A. Pandey, R. Rai, M. Pal, S. Pandey, Phys. Chem. Chem. Phys. 2014 16, 1559-1568.

[28] M. Pal, R. Rai, A. Yadav, R. Khanna, G. A. Baker, S. Pandey, Langmuir 2014, 30, 13191-13198.

[29] V. Fischer, J. Marcus, D. Touraud, O. Diat, W. Kunz, J. Colloid. Interface Sci. 2015, 453, 186-193.

[30] A. Yadav, S. Pandey, J. Chem. Eng. Data 2014, 59, 2221-2229.

[31] a) Y.-T. Liu, Y.-A. Chen, Y.-J. Xing, Chin. Chem. Lett. 2014, 25, 104 106; b) Y. Dai, G.-J. Witkamp, R. Verpoorte, Y. H. Choi, Food Chem. 2015, 187, 14-19.

[32] For general reviews, see: a) Q. Zhang, K. De Oliveira Vigier, S. Royer, F. Jérôme, Chem. Soc. Rev. 2012, 41, 7108-7146; b) B. Tang, K. H. Row, Monatsh. Chem. 2013, 144, 1427-1454; c) A. Pavia, R. Craveiro, I. Aroso, M. Martins, R. L. Reis, A. R. C. Duarte, ACS Sustainable Chem. Eng. 2014, 2, 1063-1071; d) J. García-Álvarez, Deep eutectic solvents and their applications as new green and biorenewable reaction media, in Handbook of Solvents, Vol. 2 (Ed.: G. Wypych), ChemTec Publishig, Toronto, 2014, pp. 813-844

[33] a) P. Domínguez de María, Z. Maugeri, Curr. Opin. Chem. Biol. 2011, 15, 220-225; b) V. Stepankova, S. Bidmanova, T. Koudelakova, Z. Prokop, R. Chaloupkova, J. Damborsky, ACS Catal. 2013, 3, 2823 2836; c) E. Durand, J. Lecomte, P. Villeneuve, Eur. J. Lipid Sci. Technol. 2013, 115, 379-385; d) P. Domínguez de María, Deep eutectic solvents (DES): promising solvent and "non-solvent" solutions for biocatalysis, in Environmentally Friendly Synthesis Using Ionic Liquids, (Eds.: J. Dupont, T. Itoh, P. Lozano, S. V. Mahotra), CRC Press, Boca Raton, 2014, pp. 67-86; e) P. Domínguez de María, F. Hollmann, Front. Microbiol. 2015, 6, DOI: 10.3389/fmicb.2015.01257.

[34] a) I. Lavilla, V. Romero, I. Costas, C. Bendicho, Trends Anal. Chem. 2014, 61, 1-10; b) F. Pena-Pereira, A. Kloskowski, J. Namieśnik, Green Chem. 2015, 17, 3687-3705.

[35] a) D. Carriazo, M. C. Serrano, M. C. Gutiérrez, M. L. Ferrer, F. del Monte, Chem. Soc. Rev. 2012,41, 4996-5014; b) F. del Monte, D. Carriazo, M. C. Serrano, M. C. Gutiérrez, M. L. Ferrer, ChemSusChem 2014, 7, 999-1009.
[36] a) Y. Dai, J. van Spronsen, G.-J. Witkamp, R. Verpoorte, Y. H. Choi, J. Nat. Prod. 2013, 76, 2162-2173; b) F. Pena-Pereira, J. Namieśnik ChemSusChem 2014, 7, 1784-1800; c) G. García, S. Aparicio, R. Ullah, M. Atilhan, Energy Fuels 2015, 29, 2616-2644; d) B. Tang, H. Zhang, K. H. Row, J. Sep. Sci. 2015, 38, 1053-1064.

[37] a) D. V. Wagle, H. Zhao, G. A.Baker, Acc. Chem. Res. 2014, 47, 22992308; b) A. Abo-Hamad, M. Hayyan, M. A. H. AlSaadi, M. A. Hashim, Chem. Eng. J. 2015, 273, 551-567.

[38] K. De Oliveira Vigier, G. Chatel, F. Jérôme, ChemCatChem 2015, 7, 1250-1260.

[39] A revision on the recent advances in the use of DES in Organic Reactions has appeared during the preparation of this microreview: $P$. Liu, J.-W. Hao, L.-P. Mo, Z.-H. Zhang, RSC Adv. 2015, 5, 48675-48704.

[40] D. Peters, Chem Ing. Tech. 2006, 78, 229-238.

[41] F. Ilgen, D. Ott, D. Kralisch, C. Reil, A. Palmberger, B. König, Green Chem. 2009, 11, 1948-1954.

[42] Q. Zhao, Z. Sun, S. Wang, G. Huang, X. Wang, Z. Jiang, RSC Adv. 2014, 4, 63055-63061.

[43] N. Azizi, M. Alipour, J. Mol. Liq. 2015, 206, 268-271.

[44] S. Gore, S. Baskaran, B. Koenig, Green Chem. 2011, 13, 1009-1013.

[45] B. S. Singh, H. R. Lobo, D. V. Pinjari, K. J. Jarag, A. B. Pandit, G. S. Shankarling, Ultrason. Sonochem. 2013, 20, 633-639.

[46] S. Bednarz, M. Fluder, M. Galica, D. Bogdal, I. Maciejaszek, J. Appl. Polym. Sci. 2014, 131, 40608/1-40608/8.

[47] M. C. Serrano, M. C. Gutiérrez, R. Jiménez, M. L. Ferrer, F. del Monte, Chem. Commun. 2012, 48, 579-581.

[48] Y. Zhang, F. Lü, X. Cao, J. Zhao, RSC Adv. 2014, 4, 40161-40169.

[49] Z. Chen, B. Zhou, H. Cai, W. Zhu, X. Zou, Green Chem. 2009, 11, 275278.

[50] Z. Chen, W. Zhu, Z. Zheng, X. Zou, J. Fluorine Chem. 2009, 131, 340 344.

[51] S. Sunitha, S. Kanjilal, P. S. Reddy, R. B. N. Prasad, Tetrahedron Lett. 2007, 48, 6962-6965.

[52] A. P. Abbott, T. J. Bell, S. Handa, B. Stoddart, Green Chem. 2005, 7 , 705-707.

[53] V. De Santi, F. Cardellini, L. Brinchi, R. Germani, Tetrahedron Lett. 2012, 53, 5151-5155.

[54] Q. Wang, X. Yao, Y. Geng, Q. Zhou, X. Lu, S. Zhang, Green Chem 2015, 17, 2473-2479.

[55] N. Azizi, E. Gholibeglo, M. Babapour, H. Ghafuri, S. M. Bolurtchian, C R. Chim. 2012, 15, 768-773.

[56] N. Azizi, Z. Manocheri, Res. Chem. Intermed. 2012, 38, 1495-1500.

[57] B. Bafti, H. Khabazzadeh, J. Chem. Sci. 2014, 126, 881-887.

[58] R. R. Jella, R. Nagarajan, Tetrahedron 2013, 69, 10249-10253.

[59] N. Azizi, S. Dezfooli, M. M. Hashemi, C. R. Chim. 2013, 16, 997-1001.

[60] P. Li, F. Ma, P. Wang, Z. Zhang, Chin. J. Chem. 2013, 31, 757-763.

[61] P. Wang, F.-P. Ma, Z.-H. Zhang, J. Mol. Liq. 2014, 198, 259-262.

[62] F. Cardellini, R. Germani, G. Cardinali, L. Corte, L. Roscini, N. Spreti, M. Tiecco, RSC Adv. 2015, 5, 31772-31786.

[63] N. Azizi, S. Dezfuli, M. M. Hahsemi, Sci. World J. 2012, 908702 (6 pages)

[64] F. Keshavarzipour, H. Tavakol, Catal. Lett. 2015, 145, 1062-1066.

[65] S. T. Disale, S. R. Kale, S. S. Kahandal, T. G. Srinivasan, R. V. Jayaram, Tetrahedron Lett. 2012, 53, 2277-2279.

[66] H. C. Hu, Y. H. Liu, B. L. Li, Z. S. Cui, Z. H. Zhang, RSC Adv. 2015, 5, 7720-7728.

[67] S. Khandelwal, A. Rajawat, Y. K. Tailor, M. Kumar, Comb. Chem. High Throughput Screening, 2014, 17, 763-769.

[68] L. Wang, M. Zhou, Q. Chen, M.-Y. He, J. Chem. Res. 2013, 598-600.

[69] a) B. L. Li, M. Zhang, H. C. Hu, X. Du, Z. H. Zhang, New J. Chem. 2014 38, 2435-2442; b) G. R. Reddy, T. R. Reddy, S. C. Joseph, K. S. Reddy, M. Pal, RSC Adv. 2012, 2, 3387-3395; c) B. L. Li, P. H. Li, X. N. Fang, C. X. Li, J. L. Sun, L. P. Mo, Z. H. Zhang, Tetrahedron 2013, 69, 7011-7018; d) N. Gupta, K. N. Singh, J. Singh, J. Mol. Liq. 2014, 199, 470-473. 
[70] B. Yu, D.-Q. Yu, H.-M. Liu, Eur. J. Med. Chem. 2015, 97, 673-698.

[71] M. M. M. Santos, Tetrahedron 2014, 70, 9735-9757.

[72] a) M. Xia, R.-Z. Ma, J. Heterocyclic Chem. 2014, 51, 539-554; b) F. Z. Macaev, N. S. Sucman, V. V. Boldescu, Russ. Chem. Bull., Int. Ed. 2014, 63, 15-25.

[73] D. R. Chandam, A. G. Mulik, D. R. Patil, M. B. Deshmukh, Res. Chem. Intermed. 2015, in press (DOI: 10.1007/s11164-015-2093-3).

[74] a) B. Karmakar, A. Nayak, J. Banerji, Tetrahedron Lett. 2012, 53 , 5004-5007; b) G. S. Hari, Y. R. Lee, Synthesis 2010, 3, 453-464; c) S. J. Chai, Y.-F. Lai, J.-Ch. Xu, H. Zheng, Q. Zhu, P.-F. Zhang, Adv. Synth Catal. 2011, 353, 371-375.

[75] a) A. Mobinikhaledi, A. K. Amiri, Res. Chem. Intermed. 2015, 41, 2063 2070; b) M. Bakavoli, H. Eshghi, M. Rahimizadeh, M. R. Housaindokht, A. Mohammadi, H. Monhemi, Res. Chem. Intermed. 2015, 41, 3497 3505.

[76] R. C. Morales, V. Tambyrajah, P. R. Jenkins, D. L. Davies, A. P. Abbott, Chem. Commun. 2004, 158-159.

[77] A. P. Abbott, G. Capper, D. L. Davies, R. K. Rasheed, V. Tambyrajah, Green Chem. 2002, 4, 24-26.

[78] G. Imperato, E. Eibler, J. Niedermaier, B. König, Chem. Commun. 2005 , 1170-1172.

[79] N. Azizi, Z. Yadollahy, A. Rahimzadeh-Oskooee, Tetrahedron Lett. 2014, 55, 1722-1725.

[80] a) U. N. Yadav, G. S. Shankarling, J. Mol. Liq. 2014, 195, 188-193; b) V. Krishnakumar, N. G. Vindhya, B. K. Mandal, F. R. N. Khan, Ind. Eng. Chem. Res. 2014, 53, 10814-10819.

[81] N. Azizi, E. Batebi, Catal. Sci. Technol. 2012, 2, 2445-2448.

[82] Z. Y. Duan, Y. L. Gu, Y. Q. Deng, Catal. Commun. 2006, 7, 651-656.

[83] U. B. Patil, A. S. Singh, J. M. Nagarkar, RSC Adv. 2014, 4, 1102-1106.

[84] P. J. Cragg, K. Sharma, Chem. Soc. Rev. 2012, 41, 597-607.

[85] J. Cao, Y. H. Shang, B. Qi, X. Z. Sun, L. Zhang, H. W. Liu, H. B. Zhang, X. H. Zhou, RSC Adv. 2015, 5, 9993-9996.

[86] a) S. Hu, Z. Zhang, Y. Zhou, B. Han, H. fan, W. Li, J. Song, Y. Xie, Green Chem. 2008, 10, 1280-1283; b) K. De Oliveira Vigier, A Benguerba, J. Barrault, F. Jérôme, Green Chem. 2012, 14, 285-289; c) A. A. Assanosi, M. M. Farah, J. Wood, B. Al-Duri, RSC Adv. 2014, 4, 39359-39364.

[87] N Azizi, M. Khajeh, M. Alipour, Ing. Eng. Chem. Res. 2014, 53, 15556115565.

[88] D.-y. Dai, L. Wang, Q. Chen, M.-Y. He, J. Chem. Res. 2014, 38, 183185

[89] L. Wang, D.-Y. Dai, Q. Chen, M.-Y. He, Asian J. Org. Chem. 2013, 2, 1040-1043.

[90] S. B. Phadtare, G. S. Sharkarling, Green Chem. 2010, 12, 458-462.

[91] L. Wang, K.-q. Zhu, Q. Chen, M.-y. He, Dyes and Pigments 2015, 112, 274-279.

[92] N. Azizi, E. Batebi, S. Bagherpour, H. Ghafuri, RSC Adv. 2012, 2, 2289-2293.

[93] D. Saberi, J. Akbari, S. Mahdudi, A. Heydari, J. Mol. Liq. 2014, 196, 208-210.

[94] B. Singh, H. Lobo, Catal. Lett. 2011, 141, 178-182.

[95] A. S. Singh, S. S. Shendage, J. M. Nagarkar, Tetrahedron Lett. 2014, $55,7243-7246$

[96] A. Kumar, R. D. Shukla, D. Yadav, L. P. Gupta, RSC Adv. 2015, 5, 52062-52065.

[97] A. K. Sanap, G. S. Shankarling, RSC Adv. 2014, 4, 34938-34943.

[98] Y. A. Sonawane, S. B. Phadtare, B. N. Borse, A. R. Jagtap, G. S. Sharkarling, Org. Lett. 2010, 12, 1456-1459.

[99] S. B. Phadtare, K. J, Jarag, G. S. Shankarling, Dyes Pigments 2013, 97, 105-112.

[100] B. N. Borse, S. R. Shukla, Y. A. Sonawane, G. S. Shankarling, Synth. Commun. 2013, 43, 865-876.

[101] S. Liu, Y. Ni, W. Wei, F. Qiu, S. Xu, A. Ying, J. Chem. Res. 2014, 38, 186-188.
[102] For other example of Knoevenagel condensation in DES, see: I. Hawkins, S. T. Handy, Tetrahedron 2013, 69, 9200-9204.

[103] N. Azizi, M. Edrisi, Monatsh Chem. 2015, 146, 1695-1698.

[104] S. Handy, K. Lavender, Tetrahedron Lett. 2013, 54, 4377-4379.

[105] S. Handy, M. Wright, Tetrahedron Lett. 2014, 55, 3440-3442.

[106] B. S. Singh, H. R. Lobo, D. V. Pinjari, K. J. Jarag, A. B. Pandit, G. S. Sharkarling, Ultrason. Sonochem. 2013, 20, 287-293.

[107] P. A. More, B. L. Gadilohar, G. S. Sharkarling, Catal. Lett. 2014, 144 1393-1398.

[108] H. R. Lobo, B. S. Singh, G. S. Sharkarling, Green Chem. Lett. Rev. 2012, 5, 487-533

[109] P. M. Pawar, K. J. Jarag, G. S. Sharkarling, Green Chem. 2011, 13 2130-2134.

[110] S. Handy, N. M. Westbrook, Tetrahedron Lett. 2014, 55, 4969-4971.

[111] a) S. Pednekar, R. Bhalerao, N. Ghadge, J. Chem. Sci. 2013, 125, 615621. For another contribution, see: b) L. Wang, K.-Q. Zhu, Q. Chen, M.Y. He, Green Process. Synth. 2014, 3, 457-461.

[112] a) N. Azizi, S. Dezfooli, M. Khajeh, M. M. Hashemi, J. Mol. Liq. 2013 186, 76-80. For other contributions, see: b) N. Azizi, M. Mariami, M Edsiri, Dyes Pigments 2013, 100, 215-221. c) N. Azizi, S. Dezfooli, M. M. Hashemi, J. Mol. Liq. 2014, 194, 62-67. d) A. Chaskar, Lett. Org Chem. 2014, 11, 480-486

[113] N. Azizi, S. Dezfooli, M. M. Hashemi, C. R. Chimie 2013, 16, 10981102

[114] H. R. Lobo, B. S. Singh, G. S. Sharkarling, Catal. Commun. 2012, 27, 179-183.

[115] a) N. Azizi, E. Gholibeglo, RSC Adv. 2012, 2, 7413-7416. b) N. Azizi, M. Khajeh, M. Hasani, S. Dezfooli, Tetrahedron Lett. 2013, 54, 5407-5410. c) N. Azizi, M. Marimi, Environ. Chem. Lett. 2013, 11, 371-376.

[116] N. Azizi, Z. Yadollahy, A. Rahimzadeh-Oskooee, Synlett 2014, 25, 1085-1088.

[117] J. García-Álvarez, Deep eutectic solvents: Environmentally-friendly media for metal-catalyzed organic reactions, in Green Technologies for the Environment, (Eds.: R. Luque, O. Obare), ACS books, New York, 2015, pp. 37-53

[118] C. Vidal, J. García-Álvarez, A. Hernán-Gómez, A. R. Kennedy, E. Hevia, Angew. Chem. 2014, 126, 6079-6083; Angew. Chem. Int. Ed. 2014, 53 , 5969-5973.

[119] a) V. Mallardo, R. Rizzi, F. C. Sassone, R. Mansueto, F. M. Perna, A Salomone, V. Capriati, Chem. Commun. 2014, 50, 8655-8658; b) F. C. Sassone, F. M. Perna, A. Salomone, S. Florio, V. Capriati, Chem. Commun. 2015, 51, 9459-9462.

[120] F. llgen, B. König, Green Chem. 2009, 11, 848-854.

[121] a) L. Zhang, H. Yu, BioResources 2013, 8, 6014-6025. b) L.-X. Zhang, H. Yu, H.-B. Yu, Z. Chen, L. Yang, Chin. Chem. Lett. 2014, 25, 1132 1136

[122] N. Guajardo, C. Carlesi, A. Aracena, ChemCatChem 2015, 7, 24512454 .

[123] J. Lu, X.-T. Li, E.-Q. Ma, L.-P. Mo, Z.-H. Zhang, ChemCatChem 2014, 6, 2854-2859.

[124] X. Marset, J. M. Pérez, D. J. Ramón, Green Chem. 2015, 17, in press. DOI: 10.1039/C5GC01745A

[125] C. Vidal, F. J. Suárez, J. García-Álvarez Catal. Commun. 2014, 44, 7679.

[126] G. Imperato, S. Höger, D. Lenoir, B. König, Green Chem. 2006, 8, 1051-1055.

[127] a) F. Jérôme, M. Ferreira, H. Bricout, S. Menuel, E. Monflier, S. Tilloy, Green Chem. 2014, 16, 3876-3880; b) M. Ferreira, F. Jérôme, H. Bricout, S. Menuel, D. Landy, S. Fourmentin, S. Tilloy, E. Monflier, Catal. Lett. 2015, 63, 62-65.

[128] G. Imperato, R. Vasold, B. König, Adv. Synth. Catal. 2006, 348, 2243 2247.

[129] M. J. Rodríguez-Álvarez, C. Vidal, J. Díez, J. García-Álvarez, Chem. Commun. 2014, 50, 12927-12929.

[130] C. Vidal, L. Merz, J. García-Álvarez, Green Chem. 2015, 17, 3870-3878. 
[131] J. T. Gorke, F. Srienc, R. J. Kazlauskas, Chem. Commun. 2008, 12351237.

[132] Z. Maugeri, W. Leitner, P. Domínguez de María, Eur. J. Org. Chem. 2013, 4223-4228.

[133] Z. Maugeri, P. Domínguez de María, J. Mol. Catal. B: Enzym. 2014 107, 120-123.

[134] Z. Maugeri, P. Domínguez de María, ChemCatChem 2014, 6, 1535 1537.

[135] C. R. Müller, I. Lavandera, V. Gotor-Fernández, P. Domínguez de María, ChemCatChem 2015, 7, 2654-2659.

[136] a) C. R. Müller, I. Meiners, P. Domínguez de María, RSC Adv. 2014, 4, 46097-46101, b) E. Masolo, S. Palmieri, M. Benaglia, V. Capriati, F. M.

Perna, Green Chem. 2016, 18, in press. DOI: $10.1039 / \mathrm{c5gc01855b;} \mathrm{c)}$ R. Martínez, L. Berbegal, G. Guillena, D. J. Ramón, Green Chem. 2016, 18, in press. DOI: 10.1039/c5gc02526e.

[137] B. S. Singh, H. R. Lobo, G. S. Shankarling, Catal. Commun. 2012, 24, 70-74.

[138] U. N. Yadav, G. S. Shankarling, J. Mol. Liq. 2014, 195, 188-193.

[139] A. K. Sanap, G. S. Shankarling Catal. Commun. 2014, 49, 58-62.

[140] J. M. Pérez, D. J. Ramón, ACS Sustainable Chem. Eng. 2015, 3, $2343-$ 2349. 
Entry for the Table of Contents (Please choose one layout)

Layout 1:

\section{MICROREVIEW}

21th Century DES: Social worries about the sustainability of our civilization in the Earth are forcing to change all aspects in the industrial production. In Organic Synthesis, solvents (included their production and degradation) are the main waste component in reactions. Deep eutectic solvents (and relate mixtures) offer an irresistible opportunity to improve the sustainability of processes in this century.

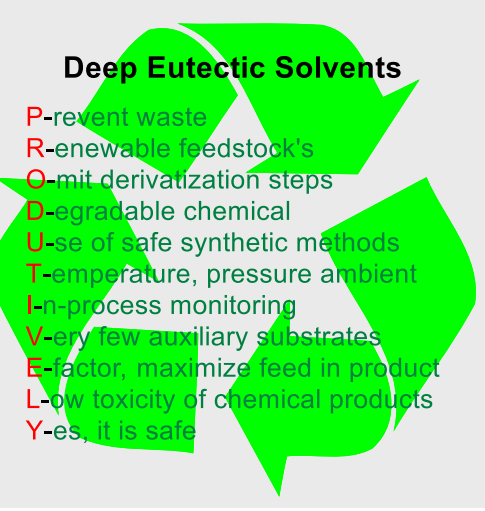

Sustainable Chemistry ${ }^{*}$

D. A. Alonso, * A. Baeza, * R. Chinchilla, ${ }^{*}$

G. Guillena, ${ }^{*}$ I. M. Pastor, ${ }^{\star} D$. J. Ramón ${ }^{\star}$

Page No. - Page No.

Deep Eutectic Solvents: The Organic Reaction Medium of the Century

*one or two words that highlight the emphasis of the paper or the field of the study

Layout 2:

\section{MICROREVIEW}

((Insert TOC Graphic here; max. width: $11.5 \mathrm{~cm}$; max. height: $2.5 \mathrm{~cm}$ : the final letter height should not be less than $2 \mathrm{~mm}$.))

Text for Table of Contents

\section{Key Topic*}

Author(s), Corresponding Author(s)*

Page No. - Page No.

Title

*one or two words that highlight the emphasis of the paper or the field of the study 